\title{
Air Pollution Exposure Indicators
}

REVIEW OF GROUND-LEVEL

MONITORING DATA AVAILABILITY AND PROPOSED CALCULATION METHOD 


\section{OECD GREEN GROWTH PAPERS}

The OECD Green Growth Strategy, launched in May 2011, provides concrete recommendations and measurement tools to support countries' efforts to achieve economic growth and development, while at the same time ensuring that natural assets continue to provide the ecosystem services on which our well-being relies. The strategy proposes a flexible policy framework that can be tailored to different country circumstances and stages of development.

This paper has been authorised for publication by Mr. Simon Upton, Director, Environment Directorate. OECD Green Growth Papers should not be reported as representing the official views of the OECD or of its member countries. The opinions expressed and arguments employed are those of the author(s). The statistical data for Israel are supplied by and under the responsibility of the relevant Israeli authorities. The use of such data by the OECD is without prejudice to the status of the Golan Heights, East Jerusalem and Israeli settlements in the West Bank under the terms of international law. It should be noted that Latvia was not an OECD member at the time of preparation of this publication. Accordingly, Latvia does not appear in the list of OECD Members and is not included in the zone aggregates. This document and any map included herein are without prejudice to the status of or sovereignty over any territory, to the

delimitation of international frontiers and boundaries and to the name of any territory, city or area.

OECD Green Growth Papers aim to describe preliminary results or research in progress by the author(s) and are published to stimulate discussion on specific topics and obtain feedback from interested audiences.

They complement the OECD Green Growth Studies series, which aims to provide in-depth reviews of the green growth issues faced by different sectors.

Comments on Green Growth Papers are welcomed, and may be sent to:

OECD Green Growth Unit, 2, rue André Pascal, 75775 PARIS CEDEX 16, France

or by email to greengrowth@oecd.org.

OECD Green Growth Papers are published on:

www.oecd.org/greengrowth

Please cite this paper as:

Turner, J. (2016), "Air Pollution Exposure Indicators: Review of Ground-Level Monitoring Data

Availability and Proposed Calculation Method", OECD Green Growth Papers, No. 2016/01, OECD Publishing, Paris.

\section{(C) OECD (2016)}

You can copy, download or print OECD content for your own use, and you can include excerpts from OECD publications, databases and multimedia products in your own documents, presentations, blogs, websites and teaching materials, provided that suitable acknowledgment of OECD as source and copyright owner is given.

All requests for commercial use and translation rights should be submitted to rights@oecd.org. 


\begin{abstract}
This paper identifies opportunities to refine OECD's indicators of air pollution and population exposure to air pollution, and their periodic production for OECD and G20 countries. First, a comprehensive review is conducted of the publicly available ground-level air monitoring data for the selected countries, including their geographic coverage, data quality, comparability, etc. Second, the paper evaluates the potential applications of ground monitoring measurements for the construction of policy-relevant and internationally comparable indicators across OECD and G20 countries. Given the limited public availability of data and the incomplete geographic coverage in countries outside of Europe and North America, this paper concludes that such data are not suitable for the development of the OECD indicators of air pollution and population exposure to air pollution that need to be harmonised across countries and over time. A hybrid approach is instead recommended as a superior alternative that draws on both satellite data combined with a chemical transport model calibrated using ground-based measurements.
\end{abstract}

JEL classification: I18, O18, Q53, R11

Keywords: ambient air pollution, outdoor air pollution, ground monitoring, particulate matter, ozone, human exposure, health

\title{
RÉSUMÉ
}

Ce rapport étudie les possibilités d'affiner les indicateurs de l'OCDE concernant la pollution de l'air et l'exposition de la population à la pollution de l'air, et leur production régulière pour les pays de l'OCDE et ceux du G20. Il propose pour commencer un examen très complet des données publiques de surveillance de l'air au niveau du sol disponibles dans les pays étudiés, en s'intéressant notamment à leur couverture géographique, la qualité des données, leur comparabilité, etc. Il évalue ensuite les possibilités de construire, à l'aide des mesures au sol, des indicateurs pertinents pour l'action publique et comparables dans les pays de l'OCDE et du G20. Après avoir constaté que les données publiques étaient limitées et que leur couverture géographique était incomplète dans les pays hors zones Europe et Amérique du Nord, le rapport conclut que ces données ne conviennent pas pour élaborer les indicateurs de l’OCDE concernant la pollution de l'air et l'exposition de la population qui doivent être harmonisés entre pays et au cours du temps. Il recommande d'opter plutôt pour une approche hybride, basée sur des données satellitaires conjuguées à un modèle de transport chimique étalonné à l'aide de données relevées au niveau du sol, qui semble offrir une meilleure alternative.

Classification JEL : I18, O18, Q53, R11

Mots clés : pollution de l'air ambiant, pollution de l'air extérieur, surveillance au sol, particules, ozone, l'exposition humaine, santé 


\section{ACKNOWLEDGEMENTS}

This paper was prepared for the OECD by Jay Turner, Associate Professor in the Department of Energy, Environmental and Chemical Engineering, Washington University in St. Louis, Missouri, USA. Michael Brauer (University of British Columbia) and Aaron Cohen (Health Effects Institute) provided helpful perspectives on the history, current status, and future plans for the GBD outdoor air pollution exposure assessments. Ivan Haščič of the OECD Secretariat provided overall guidance and final text editing. OECD colleagues including Miguel Cárdenas Rodríguez, Nathalie Girouard, Myriam Linster, Alexander Mackie, Mauro Migotto, Walid Oueslati and Valentine Rinner also provided helpful inputs on an earlier draft of the paper. Jennifer Humbert and Jacqueline Maher provided editorial assistance.

The paper was reviewed by the OECD Environmental Policy Committee and its Working Party on Environmental Information, and benefited from the comments received.

\section{FOREWORD}

Indicators on air quality and human exposure to air pollution are included in the OECD core set of Environmental indicators, in the set of OECD Green Growth indicators, in the set of OECD Well-being indicators and in the OECD's Territorial indicators.

In 2014, the OECD Working Party on Environmental Information (WPEI) requested the Secretariat to develop a detailed proposal on the way to define and calculate indicators of population exposure to air pollution, considering the pros and cons of using different data sources (e.g. remotely sensed versus monitoring data).

This paper takes a first step towards developing policy-relevant indicators of air pollution and pollution exposure that are standardised across countries and over time. It presents a comprehensive review of availability of data on air pollutant concentrations from ground monitoring stations across all OECD and G20 countries ${ }^{1}$ and examines various methodologies for the construction of the indicators at different spatial scales.

This paper should be read together with Mackie et al. (2016) that makes proposals for the indicators to be used in OECD work, and reviews the policy messages that can be derived from such indicators. Both papers build on and expand earlier work carried out by the OECD Working Party on Territorial Indicators.

It should be noted that this paper does not take into account the data on air quality collected every two years via the OECD questionnaire on the state of the environment (and derived from the EEA's Airbase for EU countries). While stemming from ground monitoring networks, these data are aggregated by countries according to criteria specified in the questionnaire. This paper explores the availability of detailed micro-data from individual monitoring stations that are available publicly and updated at regular intervals. The focus is on datasets that can be easily accessed so as to calculate internationally harmonised indicators without adding to the response burden of countries.

\footnotetext{
1 The review covers 51 countries in total (including 35 OECD member countries, 3 accession candidates, and the remaining G20 countries - including all EU 28 member states).
} 
TABLE OF CONTENTS

ABSTRACT

1. REVIEW OF PUBLICLY AVAILABLE AIR QUALITY DATA FROM GROUND-LEVEL MONITORING

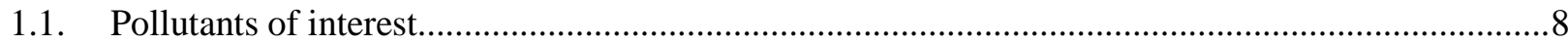

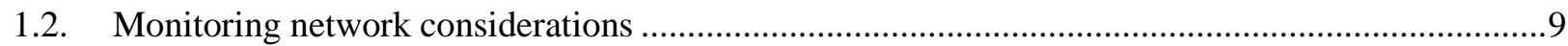

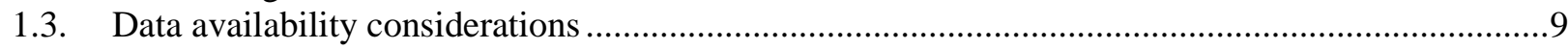

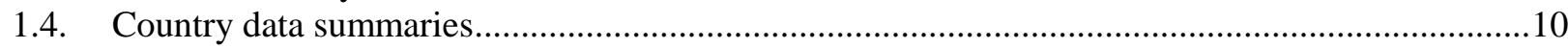

2. CANDIDATE AIR QUALITY INDICATORS USING GROUND MONITORING DATA...............20

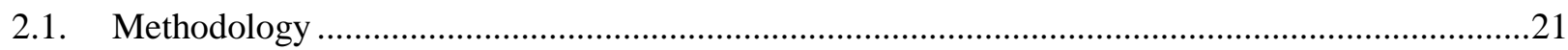

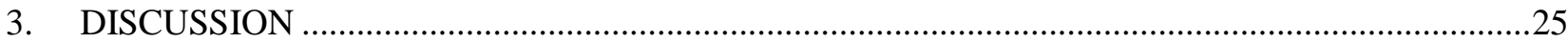

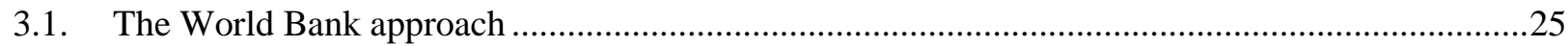

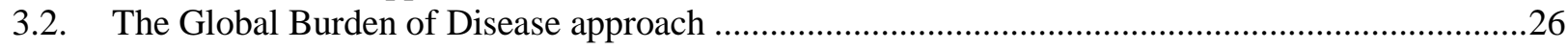

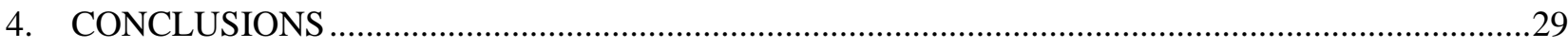

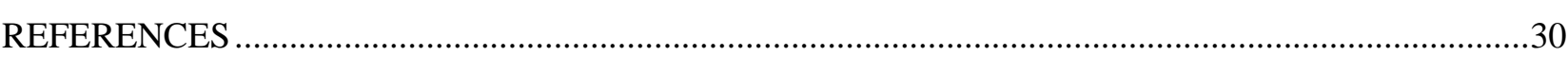

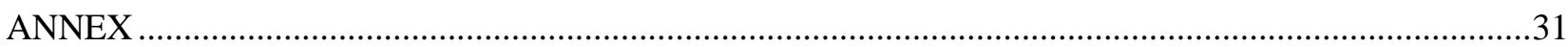

\section{Tables}

Table 1. PM2.5 annual concentration exposures for Spain, 2012, using ground-level monitoring data...... 23

Table 2. World Health Organisation air quality guidelines and interim targets (in $\quad$....g/m.............. 24

\section{Figures}

Figure 1. Number of stations in AirBase stratified by pollutant and site environment...

Figure 2. Number of background stations in AirBase stratified by pollutant and urban/rural classification 16 Figure 3. Geographic coverage of ozone measurements for the OECD and G20 countries in AirBase ...... 17 Figure 4. Geographic coverage of $\mathrm{PM}_{2.5}$ measurements for the OECD and G20 countries in AirBase ....... 18 Figure 5. Geographic coverage of $\mathrm{PM}_{10}$ measurements for the OECD and G20 countries in AirBase ....... 18 Figure 6. Geographic coverage of $\mathrm{PM}_{2.5}$ measurements for the OECD and G20 countries in AirBase....... 19 Figure A1. Population exposures to outdoor fine particulate matter (PM2.5) in 2010 using GBD2010 ..... 32 Figure A2. Population exposures to outdoor ozone (O3) in 2010 using GBD2010 ................................... 33 


\section{EXECUTIVE SUMMARY}

This paper presents a summary of a comprehensive review of available data on ground-based air quality monitoring as a contribution to further development of OECD indicators on air pollution and population exposure to air pollution that are harmonised across countries and over time. The paper provides the necessary background to understand how representative, reliable and commensurable the data from air pollution monitoring networks within and across countries are, and how the data can or cannot be used for comparing ambient air quality levels (and exposure) across OECD and G20 countries.

In recent years there has been widespread adoption of automated air quality monitors and the reporting of air quality conditions to the public in near real time. However, there remain wide disparities across countries in geographic coverage, public availability of historical data and public availability of the metadata needed for appropriate interpretation and use of the pollutant data. In Europe and North America (especially Canada and the United States) the geographic coverage is relatively good especially in densely populated areas. In these regions the metadata are sufficient to classify measurement sites according to their environment (e.g. urban versus rural, background versus traffic versus industrial) which is needed to condition the data for analysis. For Europe it is difficult to assess comparability across measurements for ambient particulate matter (PM) because, until recently, the measurement equipment was not fully specified, whereas in the United States there is a specific parameter code for PM measurements by methods that have been deemed equivalent. For the remaining third of the countries that were the focus of this assessment there are wide disparities in data availability and the data that are publicly available are typically tedious to access and use and lack adequate metadata such as geo-coordinates and site classifications.

The aforementioned issues present significant barriers to the production of population exposure to air pollution indicators that are derived primarily from the ground-level monitoring data. That stated, an indicator methodology is presented which relies solely on ground-level monitoring data and spatially resolved population data. A Geographical Information System (GIS) is used to draw buffer zones around urban, suburban, and rural background monitors (as differentiated from monitors sited roadside and in industrial zones). The entire population residing within a buffer is assigned an exposure equal to the concentration measured at the respective monitoring station. Drawbacks to this simple approach include the subjective selection of buffer sizes and assignment of an exposure estimate only to that portion of the country population residing within the buffer zones. In consideration of these issues and, more broadly, and assessment of other approaches, it is recommended that the OECD use a methodology based on air quality concentration fields routinely generated by the Global Burden of Disease (GBD) team.

Finally, the OECD should periodically reassess the availability of ground-level air quality monitoring network data because the accessibility is likely to dramatically improve in forthcoming years. 


\section{SYNTHÈSE}

Ce rapport présente la synthèse d'une étude très complète des données disponibles de surveillance de la qualité de l'air au niveau du sol qui contribuera à l'élaboration d'indicateurs de l'OCDE concernant la pollution de l'air et l'exposition de la population à la pollution de l'air, harmonisés entre les pays de l'OCDE et dans le temps. Il apporte les éléments d'information nécessaires pour évaluer la représentativité, la fiabilité et l'homogénéité des données des réseaux de surveillance de la pollution de l'air des pays, et si ces données peuvent, ou non, être utilisées pour comparer les niveaux de qualité de l'air ambiant (et d'exposition) des pays de l'OCDE et du G20.

Ces dernières années ont été marquées par l'adoption généralisée de systèmes de surveillance automatisés de la qualité de l'air et par la diffusion au public d'informations sur la qualité de l'air pratiquement en temps réel. Toutefois, la couverture géographique, la disponibilité des données historiques et la disponibilité des métadonnées nécessaires pour interpréter et utiliser correctement les données sur les polluants varient considérablement selon les pays. En Europe et en Amérique du Nord (plus particulièrement au Canada et aux États-Unis) la couverture géographique est relativement bonne, surtout dans les zones densément peuplées. Dans ces régions, les métadonnées sont suffisantes pour classer les sites de mesure selon leur environnement (zones urbaines/rurales, pollution de fond/à proximité du trafic/industrielle) ce qui est nécessaire pour traiter les données aux fins de l'analyse. Dans le cas de l'Europe il est difficile d'évaluer la comparabilité des mesures des concentrations de particules (PM) dans l'air ambiant car, jusqu'à récemment, les équipements de mesure n'étaient pas précisément spécifiés, alors qu'aux États-Unis, il existe un code de paramétrage spécifique pour la mesure des PM à l'aide de méthodes considérées comme équivalentes. Dans le tiers restant des pays considérés dans la présente étude, le degré de disponibilité des données est très variable et les données publiques sont généralement difficiles à trouver et à utiliser et manquent de métadonnées adéquates (coordonnées géographiques et classifications des sites, notamment).

Les problèmes évoqués ci-dessus font qu'il est difficile de produire des indicateurs de l'exposition de la population à la pollution de l'air en se basant principalement sur les données de surveillance au sol. Une méthodologie est cela dit présentée pour mettre au point des indicateurs uniquement à partir des données de surveillance au sol et de données démographiques résolues spatialement. Un Système d'information géographique (GIS) est utilisé pour tracer des aires de représentation autour des stations de surveillance de la pollution de fond en milieu urbain, suburbain et rural (par opposition aux stations situées à proximité des voies de circulation et des zones industrielles). On considère que l'exposition de toute la population résidant dans le périmètre défini est égale à la concentration mesurée dans la station de surveillance correspondante. Cette méthode simple présente certains inconvénients : la taille des aires de représentation est fixée de façon subjective et seule la portion de la population résidant dans les aires de représentation se voit attribuer un niveau d'exposition. Compte tenu de ces considérations, et plus généralement de l'évaluation des autres approches, il est recommandé que l'OCDE utilise une méthodologie basée sur les données zonées de qualité de l'air générées systématiquement par l'équipe de gestion du GBD (Global Burden of Disease).

Enfin, l’OCDE devrait périodiquement réévaluer la disponibilité des données des réseaux de surveillance de la qualité de l'air au niveau du sol, qui devraient devenir beaucoup plus accessibles dans les années à venir. 


\section{REVIEW OF PUBLICLY AVAILABLE AIR QUALITY DATA FROM GROUND-LEVEL MONITORING}

\subsection{Pollutants of interest}

A range of air pollutants are routinely monitored depending on the country network objectives. For this study, the parameter list was constrained to the five pollutants for which WHO's Air Quality Guidelines (AQG) have been set $-\mathrm{NO}_{2}$, ozone $\left(\mathrm{O}_{3}\right)$, particulate matter less than $2.5 \mathrm{~mm}$ aerodynamic diameter $\left(\mathrm{PM}_{2.5}\right), \mathrm{PM}_{10}$, and sulphur dioxide $\left(\mathrm{SO}_{2}\right)$. Basic characteristics of these pollutants are as follows:

$\mathbf{P M}_{2.5}$. Ambient fine particulate matter (PM smaller than $2.5 \mu \mathrm{m}$ ) can be directly emitted by sources such as combustion processes (primary PM) or formed in the atmosphere by the conversion of gases to particles (secondary PM). In many airsheds the PM is largely regional in nature with secondary PM dominating over primary PM; in other airsheds primary PM - especially from combustion sources - can have a dominant influence. In the former case a monitor can have a large spatial zone of representation while in the latter case that zone will be smaller. ${ }^{2}$

$\mathbf{P M}_{10}$. This PM fraction includes fine PM plus a portion of the coarse PM size mode which are larger particles typically from re-suspended dust, grinding processes, and sea spray. Coarse PM exhibits greater spatial variability and thus monitoring sites tend to have a smaller spatial zone of representation for $\mathrm{PM}_{10}$ than for $\mathrm{PM}_{2.5}$.

$\mathbf{S O}_{2}$. Sulphur dioxide is primarily emitted from the combustion of sulphur-bearing fuel such as coal and oil. In some countries vehicle fuels can be a significant source of $\mathrm{SO}_{2}$ while other countries have strict limits on the sulphur content in fuel. $\mathrm{SO}_{2}$ tends to exhibit high spatial variability, especially in areas with low sulphur vehicle fuels, because the major emission sources are point sources such as electric utility power plants and industrial combustors. In the United States the $\mathrm{SO}_{2}$ monitoring network has been reconfigured to focus on point source emissions.

$\mathbf{N O}_{2}$. Nitrogen dioxide is also a product of combustion, arising from either the nitrogen in fuel ${ }^{3}$ or the nitrogen in air that is converted to nitrogen oxides at high combustion temperatures. Motor vehicles, industrial combustors, and electric utility power plants are all major sources of nitrogen oxides. Whether emitted as $\mathrm{NO}$ or $\mathrm{NO}_{2}$, these two compounds cycle and thus it is common to also measure nitrogen oxides $\left(\mathrm{NO}_{\mathrm{x}}\right.$, the sum of $\mathrm{NO}$ and $\mathrm{NO}_{2}$ ) but health-based standards are for $\mathrm{NO}_{2}$ only. $\mathrm{NO}_{2}$ concentrations are typically elevated near roadways and in the United States the $\mathrm{NO}_{2}$ monitoring network has been recently been expanded to focus on near roadway measurements.

$\mathbf{O}_{3}$. Ozone is not directly emitted from sources but rather is formed in the atmosphere by chemical reactions involving volatile organic compounds (VOC) and nitrogen oxides. Concentrations tend to be relatively uniform over urban scales and are typically lower in the urban core areas or next to roadways because fresh NO emissions from motor vehicles can locally consume ozone yet lead to elevated ozone

\footnotetext{
${ }^{2}$ In practice it is difficult to generalise the conditions for which secondary PM dominates primary PM, this is because it varies by region and even by season depending on the mix of emission sources.

${ }^{3}$ Over the past few decades there has been a shift in the importance of fuel $\mathrm{NO}_{\mathrm{x}}$. Due to availability of low- $\mathrm{NO}_{\mathrm{x}}$ technologies for coal-fired power plants, fuel $\mathrm{NO}_{\mathrm{x}}$ has become relatively more important (although not dominant).
} 
concentrations farther downwind. Ozone typically has a large regional contribution with an urban increment on top of the regional baseline.

The focus of this analysis is primarily on $\mathrm{PM}_{2.5}$ and $\mathrm{O}_{3}$. $\mathrm{PM}_{2.5}$ is accepted to be of greatest global concern for adverse health outcomes from chronic exposures. There are also known adverse outcomes for elevated acute exposures. Chronic and acute exposures to $\mathrm{PM}_{2.5}$ have been linked to a wide range of health endpoints including but not limited to cardiac and respiratory impacts. On the other hand, ozone exposure concern is primarily motivated by its adverse impact on respiratory health. Brauer et al. (2012) provide additional rationale for prioritising these two pollutants.

\subsection{Monitoring network considerations}

Country and regional agencies responsible for air quality monitoring take a wide range of approaches to network design and implementation which reflect the varying objectives and available resources. Some networks are designed to co-site as many measurements as possible which can reduce infrastructure investment and provide rich data sets for air quality model evaluation. However, this approach has the drawback that the same site might have different spatial zones of representation for the different pollutants. For example, a site near an industrial zone with high $\mathrm{SO}_{2}$ emissions might have a small spatial zone of representation for $\mathrm{SO}_{2}$ (i.e. classified as an industrial site) but a large spatial zone of representation for ozone (e.g. classified as a background site).

Other networks are designed to be a mixture of population-exposure and emission source-oriented sites with only a subset of pollutants measured at a given station to meet these specific monitoring objectives. Care must be taken to distinguish these types of sites when measuring population exposures because the source-oriented sites typically have a small spatial zone of representation. For example, $\mathrm{SO}_{2}$ is emitted primarily from the combustion of sulphur-bearing fuel. In countries with advanced air pollution control devices on coal-fired electric utility power plants and limits on the sulphur content in transportation fuels, emissions are primarily from industrial sources. In the United States, many $\mathrm{SO}_{2}$ monitors are sited very close to such industrial sources and, while they can indicate exposures in the neighbourhood immediately adjacent to the industrial facility, they tend to severely overestimate population-weighted exposures at larger (e.g. urban) scales. Conversely, if the monitors are at locations far from $\mathrm{SO}_{2}$ sources they tend to underestimate population-weighted exposures over areas that include major emission sources.

These concerns highlight the importance of metadata to describe and classify the monitoring environment. Ideally the site environment would be classified separately for each pollutant. In practice, however, a single classification is typically specified for the site rather than classifying the environment for each pollutant.

\subsection{Data availability considerations}

Data availability was assessed by conducting web searches. The approach was intentionally constrained to focus on publicly available data. In some cases it might be possible request data from the responsible organisation through personal correspondence but this was beyond the scope of this study. In many countries there are multiple networks with varying degrees of coordination across the responsible agencies. For example, in India there is a nationwide network operated by the Central Pollution Control Board (CPCB) and each state also has its own network (e.g. the Maharashtra Pollution Control Board and Delhi Pollution Control Committee). In other countries such as Australia and South Africa the monitoring appears to be completely delegated to the regions (e.g. states or territories). This can lead to challenges in accessing data because in most of these cases the data remains decentralised and web sites must be consulted for each of the regional agencies. 


\subsection{Country data summaries}

The initial intent was to summarise the data availability by country in a table with a rating scale reflecting geographic coverage (e.g. all country data available from a single web site, data available only at the regional level), the type of data reported (native data which are typically hourly or daily values versus summary statistics such as monthly or annual averages), public availability of data, comprehensiveness of metadata, etc. However, there were such distinct characteristics of these measures across countries that numerous qualifications were required which diminished the value of this approach and thus a narrative summary is provided.

For many countries, regional and national data are available in real time from the $\mathrm{web}^{4}$ and are reported as concentrations or as air quality index (AQI) by pollutant. These data are not archived but in principle the data could be "scraped" every hour to construct a database of unvalidated concentration values. In many cases the web site has a scalable map which can be used to identify station locations when such metadata are otherwise unavailable.

WHO compiles $\mathrm{PM}_{2.5}$ and $\mathrm{PM}_{10}$ concentration data for more than 1600 cities. The most recent update was in 2014 and includes annual mean data ranging from 2008 to 2013 depending on the site. ${ }^{5}$ A single value is reported for each city; in some cases the data are from a single monitoring station while in other cases the reported value is an average over multiple stations. While these data are potentially useful they do not provide the geographic coverage that is a focus of this paper.

\section{OECD member countries}

An important number of OECD countries are included in the European Environmental Agency's AirBase dataset. These countries are: Austria, Belgium, Switzerland, Czech Republic, Germany, Denmark, Spain, Estonia, Finland, France, Greece, Hungary, Ireland, Iceland, Italy, Luxembourg, Netherlands, Norway, Poland, Portugal, Slovak Republic, Slovenia, Sweden, Turkey and the United Kingdom. The Airbase dataset is briefly summarised at the end of this Section.

Australia: Country-level historical air quality data appear to be publicly available but are not consolidated. Data access is at the state or territory level through the respective administrative agency and there are eight states/territories with population greater than 2500 (the smallest of these eight has population 230000 ). For example, for New South Wales there is a web interface where data can be queried for a specified time period with the option to select multiple pollutants and stations. ${ }^{6}$ Data can be queried as daily, monthly, or annual averages and are provided as an MS Excel spreadsheet. Data for the current year are raw while data for previous years are validated. Measurements [number of stations] for 2013 include $\mathrm{NO}_{2}$ [24], $\mathrm{O}_{3}$ [44], $\mathrm{PM}_{2.5}$ [14], $\mathrm{PM}_{10}$ [40] and $\mathrm{SO}_{2}$ [17]. Metadata are presented on web pages stratified by five regions within the territory; these include the site coordinates and parameters measured. The site metadata was last updated in September 2013. As another example, for Victoria a PDF format annual report is published, ${ }^{7}$ most recently for 2013, which lists monthly average and annual average concentrations. Measurements [number of stations] for 2013 include $\mathrm{NO}_{2}$ [14], $\mathrm{O}_{3}$ [12], $\mathrm{PM}_{2.5}$ [6 including 3 automated and 3 manual], $\mathrm{PM}_{10}$ [29 including 27 automated and 2 manual] and $\mathrm{SO}_{2}$ [7]. There were large data gaps for four of the six $\mathrm{PM}_{2.5}$ station datasets. Data completeness is reported but no other metadata are reported.

\footnotetext{
${ }^{4}$ e.g. http://aqicn.org/map/

${ }^{5}$ http://apps.who.int/gho/data/view.main.AMBIENTCITY2011?lang=en

${ }^{6}$ www.environment.nsw.gov.au/AQMS/search.htm

${ }^{7}$ www.epa.vic.gov.au/our-work/monitoring-the-environment/monitoring-victorias-air/monitoring-results
} 
Canada: Country-level historical air quality data are publicly available through Environment Canada's National Air Pollution Surveillance (NAPS) database. ${ }^{8}$ The database covers all monitoring stations in the country and fixed-width ASCII files from database extractions are posted to the web site. These files are periodically updated. There is one file per parameter-year that includes native data for all sites in the network. Validated data are currently available through 2013. An MS Excel spreadsheet with station and measurement metadata can also be downloaded from the web site under "NAPS Network Information”.

Chile: Country-level historical air quality data are available through a web interface ${ }^{9}$ but the dataset is not consolidated. A map with real-time pollutant-specific AQI can be displayed. The number of stations and parameters measured are not readily accessible but based on the map there appears to be about twenty stations for $\mathrm{O}_{3}, \mathrm{PM}_{2.5}$, and $\mathrm{PM}_{10}$, and about ten stations for $\mathrm{NO}_{2}$ and $\mathrm{SO}_{2}$. Clicking a site on the map and selecting "ver ficha" pulls up detailed metadata. Subsequently, clicking on "Graficos" for a given parameter pulls up a time series of the entire data record with links to downloading the native data as a semi-colon delimited file; this does suggest these data are stored in a database with a more comprehensive data extraction provided upon request. The number of stations, parameters measured, and time period of data were not assessed because of the need to individually query each station. Data are specified as validated, preliminary, and unvalidated (the most-recent data).

Israel: Country-level historical air quality concentration data are publicly available. The Israel Ministry of Environmental Protection provides real-time data as well as PDF-format annual reports with summary statistics for all monitors in the national network. ${ }^{10}$ Reports are in Hebrew and most recent data are for 2013. Historical data can be queried by site with a table generated (e.g. in MS Excel format) with the daily values for a specified pollutant and year. Detailed metadata do not appear to be publicly available.

Japan: Country-level historical air quality concentration data are available from the National Institute for Environmental Studies (NIES) ${ }^{11}$. Both annual and monthly data on $\mathrm{PM}_{2.5}$ have been accumulated since 2010 when the law requiring the government to monitor $\mathrm{PM}_{2.5}$ went in force, and both oxidant and nitrogen oxides since 1970. Hourly data from the most-recent two or more weeks can be queried by site from the Atmospheric Environmental Regional Observation System (AEROS) database ${ }^{12}$. Detailed metadata are not publicly available although the station type (e.g., general, roadside) is specified.

Korea: Country-level historical air quality data are available through a web interface but the dataset is not consolidated. Real time data are available ${ }^{13}$ and from this web site select 통계정보 and then 시도별 확정자료 to generate an MS Excel file with annual average pollutant concentrations for each of the 16 municipalities for a selected year. These data are not station specific but rather appear to be aggregated across the stations in each municipality. Data are available for $\mathrm{NO}_{2}, \mathrm{O}_{3}, \mathrm{PM}_{2.5}, \mathrm{PM}_{10}$, and $\mathrm{SO}_{2}$, and cover the period 2006-13. A station-level search can be conducted to generate a table of daily-average concentrations for a specified month. ${ }^{14}$ Thus, to construct an annual average for a single station the search must be run twelve times. No detailed metadata are publicly available.

\footnotetext{
${ }^{8}$ http://maps-cartes.ec.gc.ca/rnspa-naps/data.aspx?lang=en

${ }^{9}$ http://sinca.mma.gob.cl/

${ }^{10}$ www.sviva.gov.il/English/env topics/AirQuality/Pages/Air\%20Quality\%20Data.aspx\#GovXParagraphTitle1

${ }^{11}$ www.nies.go.jp/igreen

${ }^{12} \mathrm{http}: / /$ soramame.taiki.go.jp/DataListSel.php

${ }^{13}$ www.airkorea.or.kr/index

${ }^{14}$ www.airkorea.or.kr/pastSearch
} 
Mexico: Hourly data for the Mexico City automated monitoring station network (RAMA) can be downloaded by year for the period 1986-2014. ${ }^{15}$ Data are provided as MS Excel files with one file per pollutant $\left(\mathrm{NO}_{2}, \mathrm{O}_{3}, \mathrm{PM}_{2.5}, \mathrm{PM}_{10}, \mathrm{SO}_{2}\right.$, plus additional parameters). In 2013 the numbers of stations monitoring each pollutant were: $\mathrm{NO}_{2}$ [28], $\mathrm{O}_{3}$ [28], $\mathrm{PM}_{2.5}$ [13] $\mathrm{PM}_{10}$ [20] and $\mathrm{SO}_{2}$ [27]. Geo-coordinates are available by selecting from a station list to pull up the station-specific details. ${ }^{16}$ For the remainder of the country, there is a web interface for querying both manual and automated measurements data ${ }^{17}$ but as of April 2014 the interface did not properly work. Thus, it is not clear whether country-level historical data are publicly available; if it is available then it is not in a consolidated format. Metadata for all stations in a given state can be accessed from a list of states.

New Zealand: Country-level historical air quality data are not publicly available. Regional, district and city councils are responsible for air quality monitoring and the data management appears to be decentralised. There are some summary data in reports by the Ministry for the Environment such as annual average $\mathrm{PM}_{10}$ concentrations in various cities ${ }^{18}$.

United States: Country-level historical air quality concentration data are publicly available from the United States Environmental Protection Agency (USEPA) Air Quality System (AQS) database. There are several ways to access these data including network-wide annual summary data (annual averages and other statistics) that are posted as comma-delimited ASCII files for the period 1990-2014. ${ }^{19}$ Each file contains network-wide data for one year including $\mathrm{NO}_{2}, \mathrm{O}_{3}, \mathrm{PM}_{2.5}, \mathrm{PM}_{10}$, and $\mathrm{SO}_{2}$, and additional pollutants. Some metadata including geo-coordinates are in these files; additional metadata including site classifications can be accessed by cross-listing the site ID code with a station metadata file. For particulate matter, data are provided for both automated monitors and manual (filter-based sampling) methods. A subset of these data can be harmonised because a distinction is made for those automated methods that have been deemed equivalent to the filter-based method in a compliance monitoring context.

\section{OECD accession countries}

Colombia: Country-level historical air quality data are available through a web interface ${ }^{20}$ but the dataset is not consolidated. The number of stations and parameters measured are not readily accessible because queries are conducted by first choosing one of the 32 departments (country regions). Queries are for a single date and pull up a table with all measurements within the selected department including daily average concentrations and other statistics. There appears to be a web interface to query by date range for a station-pollutant combination but it did not function properly; however, this does suggest these data are stored in a database with a more comprehensive data extraction provided upon request. Metadata can be queried by site to pull up a web page with the environmental characteristics (e.g. local, regional) and the station address.

Costa Rica: Air quality data are not publicly available.

Lithuania and Latvia are included in the Airbase dataset. The description of the dataset and the methodology are presented in the next subsection.

\footnotetext{
${ }^{15}$ www.aire.df.gob.mx/default.php?opc='aKBh'

${ }^{16}$ www.aire.df.gob.mx/default.php?opc $=\% 27 \mathrm{ZaBhnmI}=\% 27 \& \mathrm{dc}=\mathrm{ZA}==$

${ }^{17}$ http://sinaica.inecc.gob.mx/

${ }^{18}$ www.mfe.govt.nz/more/environmental-reporting/air/air-domain-report-2014

${ }^{19}$ http://aqsdr1.epa.gov/aqsweb/aqstmp/airdata/download_files.html

${ }^{20}$ www.sisaire.gov.co:8080/faces/portal/default.jsp
} 


\section{Other $\mathbf{G 2 0}$ countries}

Argentina: Country-level historical air quality data are not publicly available. $\mathrm{NO}_{2}, \mathrm{O}_{3}$ and $\mathrm{PM}_{10}$ are measured at one-or-more of four stations in Buenos Aires. ${ }^{21}$ An Adobe Acrobat (PDF) file can be downloaded for each station-parameter-month that contains daily average concentrations and other data statistics. There are several missing months of data in the historical records, and no data are available for some parameters such as $\mathrm{O}_{3}$. Detailed metadata are not publicly available but the station-specific web pages do describe the parameters measured, general site characteristics (e.g. located in a residential area with high traffic flow and no stationary sources) and the address in terms of the nearest intersection of major roadways.

Brazil: Country-level historical air quality data are publicly available as a report in PDF format with the 2014 report including data for 2000 through 2012. ${ }^{22,23}$ These data are organised in tables that include annual average concentrations for each monitoring station with a separate table for each state-pollutant combination. Moreover, real-time data are available as a multipollutant Air Quality Index (AQI) for more than 53 stations in the Sao Paulo area ${ }^{24}$. Measurements [number of stations] include $\mathrm{NO}_{2}$ [41], $\mathrm{O}_{3}$ [12], $\mathrm{PM}_{2.5}$ [10], $\mathrm{PM}_{10}$ [49] and $\mathrm{SO}_{2}$ [10]. Data can be queried through a web interface ${ }^{25}$ by site and date (5/8/2013-present) to pull up a table with hourly data for that date only; this does suggest these data are stored in a database with a more comprehensive data extraction provided upon request. A metadata table includes the parameter measured at each station and the station address. ${ }^{26}$

China (People's Republic of) (hereafter 'China'): Country-level historical air quality concentration data are not publicly available. A web interface ${ }^{27}$ can be queried to generate a table of historical daily AQI values (including designation of the main pollutant) from 1 January 2014 to present. However, separate queries must be run for each of the 367 cities and the AQI is available only for the main pollutant on each day, which can change from day-to-day, so a time series of pollutant-specific AQI values cannot be generated. It is not clear how the city-level AQI is generated in cases where there are multiple stations in the city. China does have extensive reporting of hourly concentrations to the web and this presents an opportunity for such data to be archived through automated retrieval. ${ }^{28}$

India: Country-level historical air quality concentration data are not publicly available. The Central Pollution Control Board (CPCB) has a portal for downloading data by site and parameter over a user defined time period. ${ }^{29}$ However, as of April 2015 the database could not be successfully queried. Detailed metadata are not available. Several states have data on their respective web sites. For example, Maharashtra State Pollution Control Board has a portal to display daily-average data by site over a user defined time period. ${ }^{30}$ These data can be saved as a PDF file. Site classification (e.g. residential,

\footnotetext{
${ }^{21}$ www.buenosaires.gob.ar/agenciaambiental/monitoreoambiental/calidadaire

22 www.mma.gov.br/cidades-sustentaveis/qualidade-do-ar

${ }^{23}$ www.mma.gov.br/images/arquivo/80060/Diagnostico_Rede_de_Monitoramento_da_Qualidade_do_Ar.pdf

${ }^{24}$ http://sistemasinter.cetesb.sp.gov.br/Ar/php/mapa_qualidade_rmsp.php?id=1\#resultad

${ }^{25}$ http://sistemasinter.cetesb.sp.gov.br/Ar/php/ar_dados horarios.php

${ }^{26}$ www.cetesb.sp.gov.br/ar/Informa\%EF\%BF\%BD\%EF\%BF\%BDes-B\%EF\%BF\%BDsicas/24-

${ }^{27}$ http://datacenter.mep.gov.cn/report/air_daily/air_dairy_en.jsp

${ }^{28}$ Much of the city-level $\mathrm{PM}_{2.5}$ and $\mathrm{PM}_{10}$ data for Asian countries in the WHO database is from the Clean Air Asia's CitiesACT database. http://aqicn.org/map/

${ }^{29}$ www.cpcb.gov.in/CAAQM/mapPage/frmindiamap.aspx

${ }^{30}$ http://mpcb.gov.in/envtdata/demoPage1.php
} 
commercial, industrial) are the only metadata available. From the Andra Pradesh State Pollution Control Board web site ${ }^{31}$ only graphs with annual average data are available and the web site was most recently updated in 2006. No metadata are available. The West Bengal Pollution Control Board has a web interface to query data ${ }^{32}$ but as of April 2015 data could not be successfully downloaded. No metadata are publicly available. The Tamil Nadu Pollution Control Board publishes an annual report with monthly average concentration values for monitoring stations in Chennai. ${ }^{33}$ No metadata are publicly available.

Indonesia: Air quality data are not publicly available.

Russian Federation (hereafter 'Russia'): Country-level historical air quality data are not publicly available. Real-time data are available for more than forty stations in the Moscow area. ${ }^{34}$ Stations can be selected individually from a map and then a table can be pulled up with summary statistics, such as annualaverage concentrations, for the most-recent complete year (i.e. 2014). Upon aggregating across all five sites there are data for each of the five pollutants. No metadata are publicly available; station locations can be estimated from the scalable map.

Saudi Arabia: Air quality data are not publicly available.

South Africa: Country-level historical air quality data appear to be publicly available but these data are not consolidated. The South African Air Quality Information System (SAAQIS) ${ }^{35}$ has a web interface to query data by station and parameter for a specified time range. The output is a graph and the numerical values cannot be downloaded. There is an online form to request data by station and time range for the full suite of parameters measured at that station. However, a query would need to be executed one-by-one for each station in the network. This does suggest the network data are stored in a database with a more comprehensive data extraction provided upon request. The number of stations, parameters measured, and time period of data were not assessed because of the need to individually query each station. The web site also has a map with the monitoring stations and clicking on a station pulls up detailed metadata including geo-coordinates, site classification (e.g. residential, industrial), and a description of the conditions the site represents (e.g. "This site will be representative of pollutant concentrations associated with domestic fuel burning and give an indication of the potential human health impacts. Additionally, the impact of industries to the south may be accounted for at this site when southerly flow occurs."). Such detailed metadata is very helpful but is atypical compared to the metadata available for most other countries.

The remaining five countries reviewed in this study have been included as per the membership of the European Union (EU28) in G20. Data for these countries - including Bulgaria, Croatia, Cyprus ${ }^{36}$, Malta and Romania - are available in the Airbase dataset. The description of the dataset follows next.

\footnotetext{
${ }^{31}$ www.appcb.ap.nic.in/air\%20quality/air_quality.htm

32 http://emis.wbpcb.gov.in/airquality/showprevdata.do

33 www.tnpcb.gov.in/ambient_airquality.htm

${ }^{34}$ www.mosecom.ru/air/air-today/

${ }^{35}$ www.saaqis.org.za/Mashup.aspx

${ }^{36}$ Note by Turkey: The information in this document with reference to "Cyprus" relates to the southern part of the Island. There is no single authority representing both Turkish and Greek Cypriot people on the Island. Turkey recognises the Turkish Republic of Northern Cyprus (TRNC). Until a lasting and equitable solution is found within the context of the United Nations, Turkey shall preserve its position concerning the "Cyprus issue".

Note by all the European Union Member States of the OECD and the European Union: The Republic of Cyprus is recognised by all members of the United Nations with the exception of Turkey. The information in this document relates to the area under the effective control of the Government of the Republic of Cyprus.
} 


\section{Airbase database}

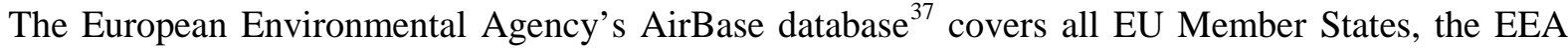
member countries and some EEA collaborating countries. It includes data for 32 of the 51 selected countries - AT, BE, BG, CH, CY, CZ, DE, DK, EE, ES, FI, FR, GB, GR, HR, HU, IE, IS, IT, LT, LU, LV, MT, NL, NO, PL, PT, RO, SE, SI, SK and TR. The database is periodically queried to generate output files posted at the aforementioned URL. All five target pollutants are included. Three tab delimited files include various yearly data statistics (e.g. annual averages) by site-pollutant-year, station metadata, and measurement configurations metadata, respectively. Validated data are currently available through 2012. Should statistics be desired that are not in the summary file, presumably these data could be provided by the EEA upon request.

The publicly available AirBase dataset files are exemplary in terms of content and format. Data from the three files do need to be merged to create a comprehensive database. One file contains metadata for all of the stations with key information such as monitoring site environment (urban, suburban, or rural; and background, traffic, or industrial), and geo-referencing data (latitude and longitude). The two environmental fields together provide important information to filter the data for calculating population exposures. For example, while people live, work, and play near major roadways and industrial zones, it is generally accepted that community-oriented monitors (background stations in AirBase terminology) are most appropriate for measuring population exposures because the traffic and industrial stations would have relatively small spatial zones of representation.

Figure 1 shows the distribution of monitoring stations in AirBase stratified by site environment (carbon monoxide is also included because it is a common traffic-dominated pollutant). The number of background stations ranges from $36 \%$ to $71 \%$ depending on the pollutant (in urban areas the range is $30 \%$ to 63\%). This demonstrates the importance of having appropriate metadata to condition the dataset to include only those stations that are broadly representative of population exposures, in this case retaining only the background stations.

Figure 2 shows how the background stations are distributed across urban, suburban, and rural classes. While most monitoring networks focus on urban areas, it can be important to have both urban and rural stations for those countries with significant rural population. This Figure also shows some of the challenges such as the relatively low number of monitors for $\mathrm{PM}_{2.5}$ which is considered to be of more importance than $\mathrm{PM}_{10}$ from the standpoint of adverse health impacts. The number of $\mathrm{PM}_{2.5}$ monitoring sites is expected to increase over time.

While Figure 2 provides measures of the total number of stations, it alone does not provide information about spatial coverage within and between countries. Figure 3 shows the geographic coverage of $\mathrm{O}_{3}$ background stations for the OECD countries in AirBase (Iceland is not shown). Geographic coverage is represented by using $25 \mathrm{~km}$ radius buffer zones around each urban and suburban monitor (purple) and $50 \mathrm{~km}$ radius buffer zones around each rural monitor (yellow) ${ }^{38}$ Rural buffer zones overlapping with the urban/suburban buffers zones have been erased. There is good geographic coverage over most of Europe with the exception of Scandinavian and south-eastern European countries. A refined analysis should be conducted by overlaying these buffer zones on a high resolution population density map to measure the population fraction in each country or region that falls within a buffer zone; this would be a better measure of coverage from a population exposure perspective.

37 www.eea.europa.eu/themes/air/air-quality/map/airbase

${ }^{38}$ These buffer zone radii are subjective but are likely indicative of what would be expected for pollutants such as $\mathrm{O}_{3}$ and $\mathrm{PM}_{2.5}$. This topic is addressed in more detail in Section 2. 
Figure 1. Number of stations in AirBase stratified by pollutant and site environment
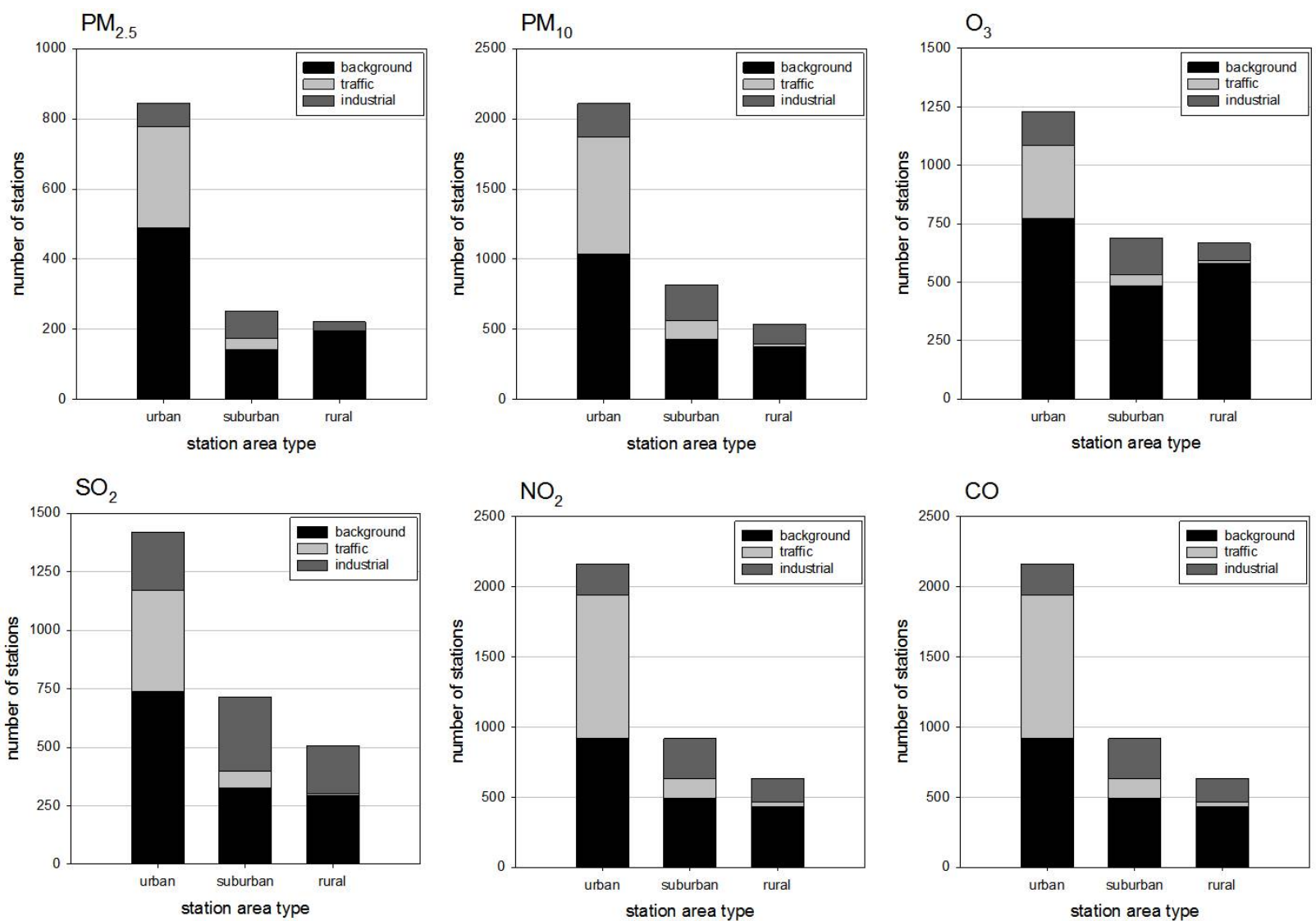

Note: The data were censored to include only those stations still operating as of 1 January 2013 to be consistent with data most recently reported for 2012.

Figure 2. Number of background stations in AirBase stratified by pollutant and urban/rural classification

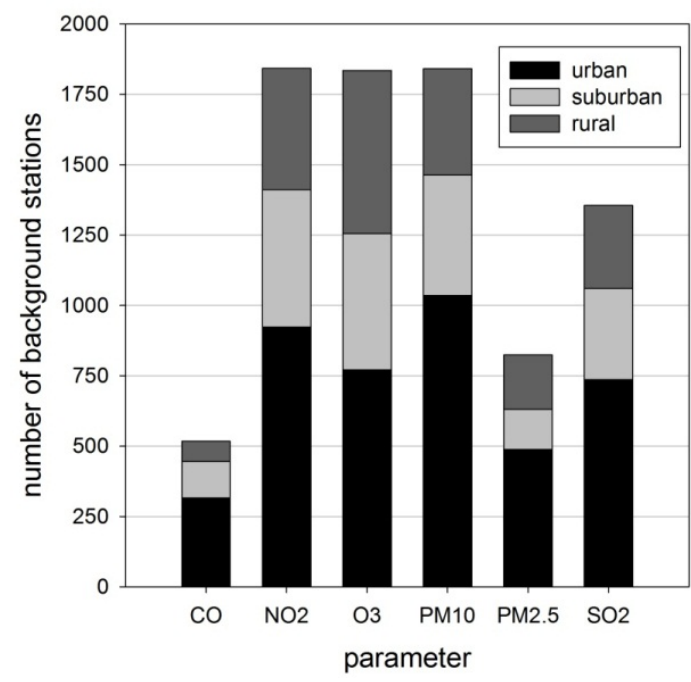

Note: The data were censored to include only those stations still operating as of 1 January 2013 to be consistent with data most recently reported for 2012 
Figure 4 shows the geographic coverage for $\mathrm{PM}_{2.5}$ using the same buffer zone radii used for the $\mathrm{O}_{3}$ map. The coverage is much sparser and suggests that these data alone might be acceptable to generate city indicators but are inadequate to generate country or region indicators. One approach to address this issue is to use supplement the $\mathrm{PM}_{2.5}$ with a proxy generated from $\mathrm{PM}_{10}$ data where available.

Figure 5 shows the geographic coverage for $\mathrm{PM}_{10}$ which is better than for $\mathrm{PM}_{2.5}$. In this case, however, the buffer zones might be too large because $\mathrm{PM}_{10}$ measurements typically have a smaller spatial zone of representation. Despite that caveat, one approach would generate $\mathrm{PM}_{2.5} / \mathrm{PM}_{10}$ ratios for areas where both measurements are made and then then use these ratios to estimate $\mathrm{PM}_{2.5}$ in areas with only $\mathrm{PM}_{10}$ data. The $\mathrm{PM}_{2.5} / \mathrm{PM}_{10}$ ratios used for these calculations could vary geographically to capture gross differences in land classification (e.g. arid regions which might be more susceptible to re-suspended dust).

Figure 6 shows the geographic coverage for $\mathrm{PM}_{2.5}$ after supplementing with $\mathrm{PM}_{10}$ data. For this case the coverage for $\mathrm{PM}_{2.5}$ is similar to the coverage for $\mathrm{O}_{3}$. In summary, the AirBase dataset includes about $60 \%$ of the selected countries and has good geographic coverage with the exception of perhaps the Nordic countries and south-eastern Europe depending on the population density distributions in those areas.

Figure 3. Geographic coverage of ozone measurements for the OECD and G20 countries in AirBase

Based on a $25 \mathrm{~km}$ radius buffer around urban and suburban monitors (purple) and a $50 \mathrm{~km}$ radius buffer around rural monitors (yellow).

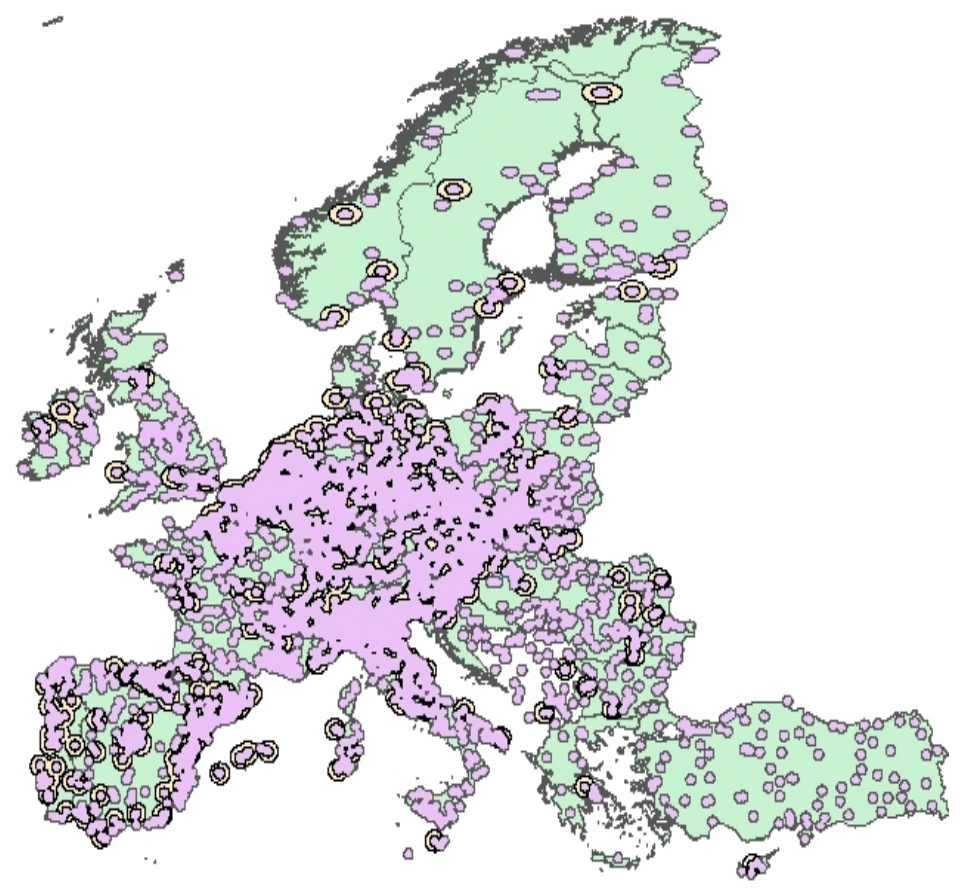


Figure 4. Geographic coverage of $\mathrm{PM}_{2.5}$ measurements for the OECD and $\mathrm{G} 20$ countries in AirBase

Based on a $25 \mathrm{~km}$ radius buffer around urban and suburban monitors (purple) and a $50 \mathrm{~km}$ radius buffer around rural monitors (yellow).

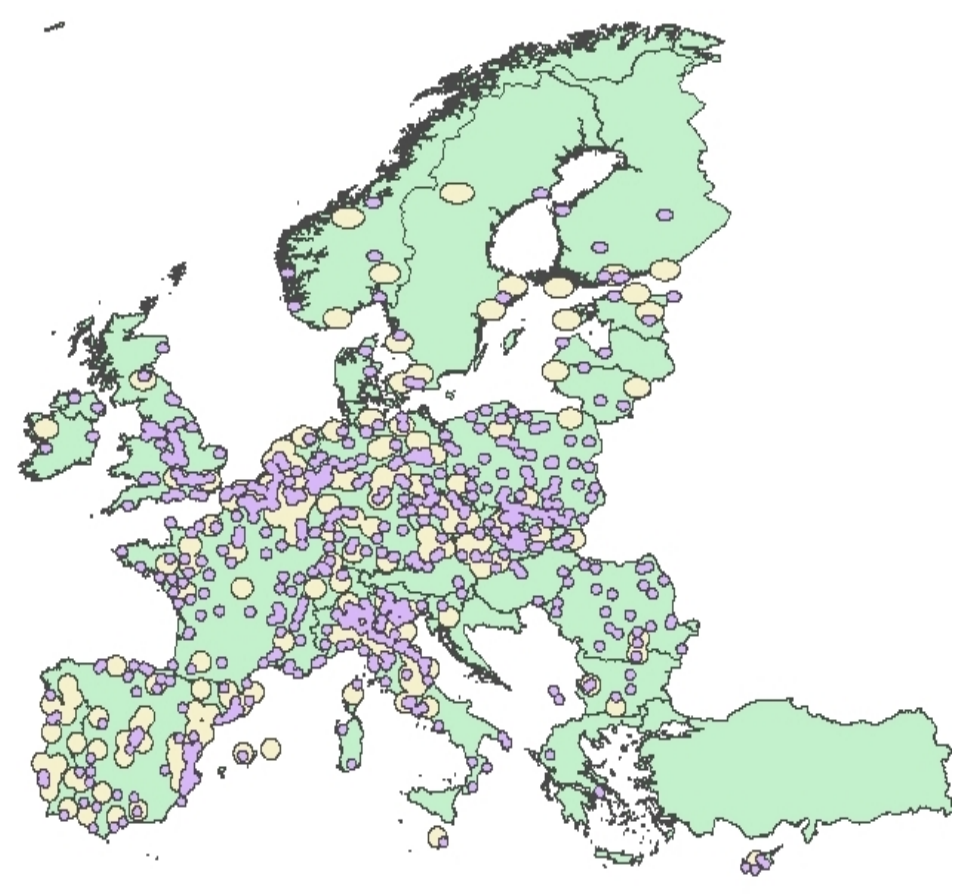

Figure 5. Geographic coverage of $\mathrm{PM}_{10}$ measurements for the OECD and $\mathrm{G} 20$ countries in AirBase

Based on a $25 \mathrm{~km}$ radius buffer around urban and suburban monitors (purple) and a $50 \mathrm{~km}$ radius buffer around rural monitors (yellow)

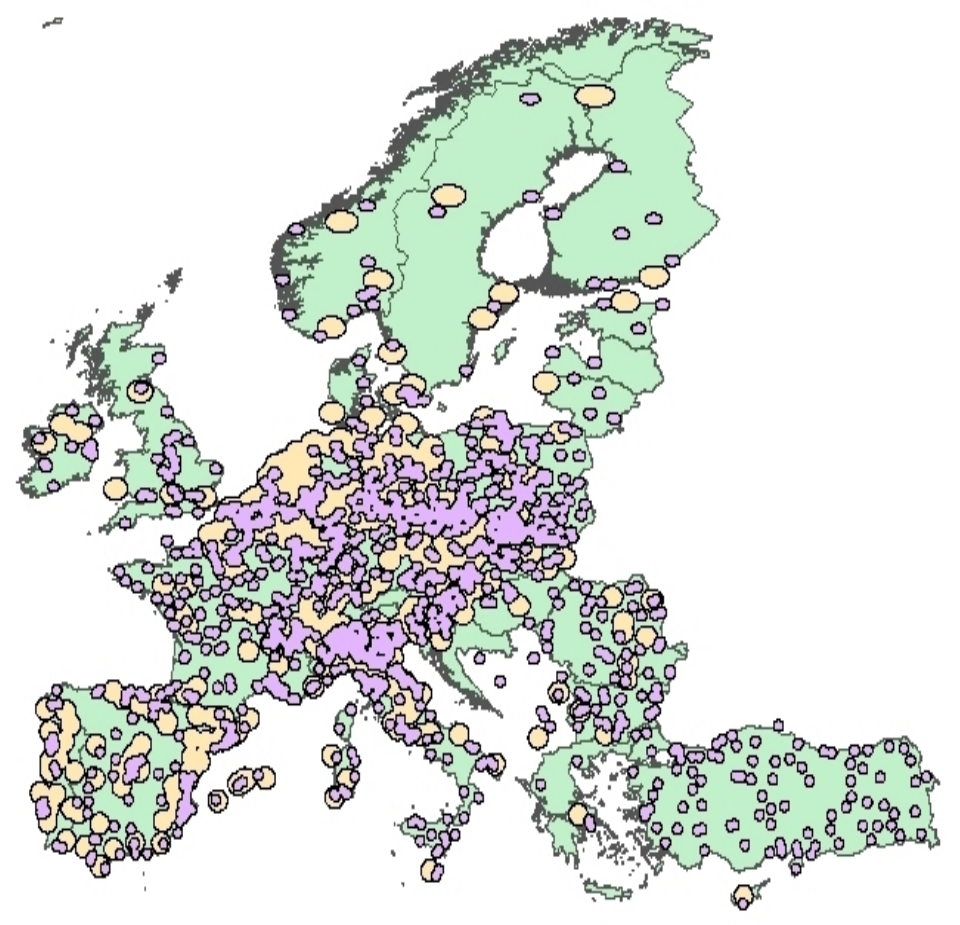



monitors (yellow), and using scaled $\mathrm{PM}_{10}$ measurements as a surrogate for $\mathrm{PM}_{2.5}$ (red)

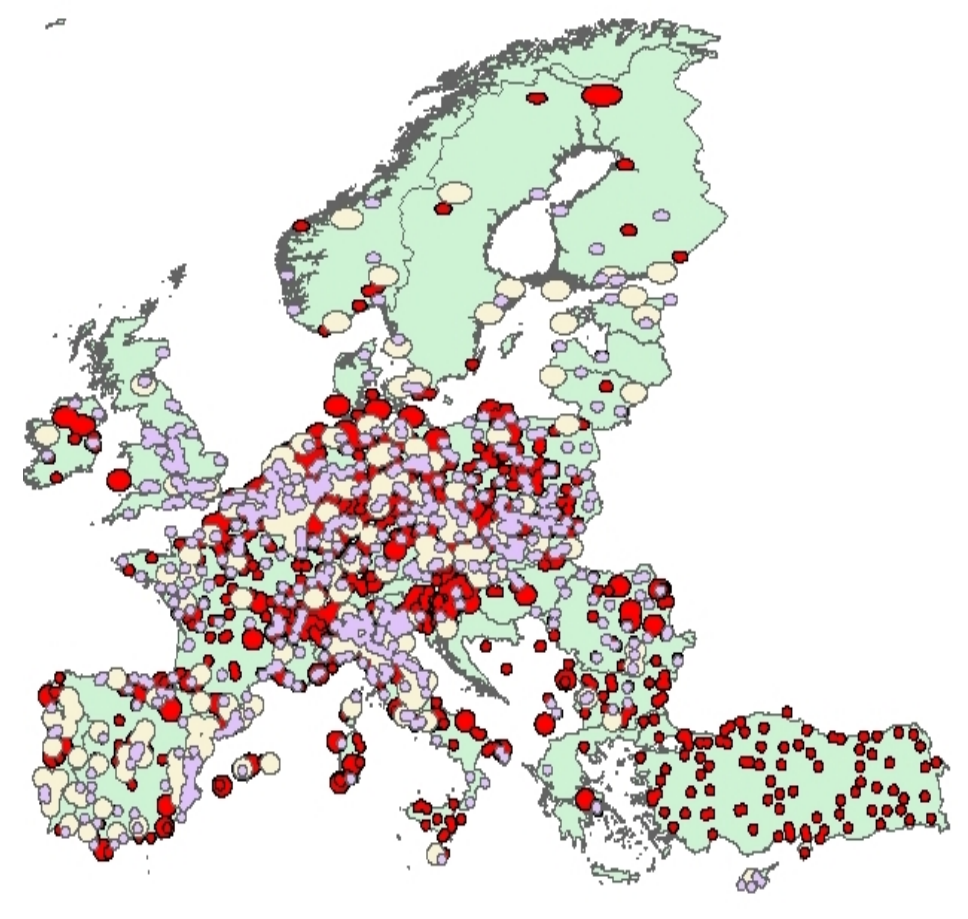

A second AirBase file contains the measurements metadata. Key information includes the pollutant measured at each station and the measurement method. EEA provides a central repository for the data but does not specify measurement methods which are at the discretion of each country. ${ }^{39}$ Virtually all of the gas pollutant data are collected using automated monitors. For $\mathrm{O}_{3} 99 \%$ of the monitors are automated (1\% are not specified and presumably automated) and $91 \%$ are by the same method (ultraviolet photometry) with $7 \%$ listed as unknown and $2 \%$ unspecified. Comparability of the gas pollutant data across the dataset should be good. For $\mathrm{PM}_{2.5}$, however, assessing comparability is more complex. A manual method based on collecting particles onto filters with offline gravimetric analysis at a laboratory is still common. After sample collection and prior to gravimetric analysis the filters are equilibrated in the laboratory at specified relative humidity (typically $40 \%$ in Europe). This approach tends to standardise the mass of water retained by the sample but can lead to differences compared to the automated measurements. There can also be differences between the automated methods depending on the method used to condition the sampled air stream to control for water content. For example, some monitors heat the air stream to a fixed temperature regardless of ambient conditions (relative humidity and temperature); this approach can remove water but also removes other semi-volatile components of the PM mass such as ammonium nitrate and certain organic compounds. Other monitors heat the air stream only when the relative humidity is high and only to a few degrees above the ambient temperature; this approach seeks to remove water yet suppress excessive loss of other semi-volatile compounds. Yet another approach uses a sophisticated conditioning protocol including dryers, heaters and coolers to remove the water yet retain the other semi-volatile compounds. Some monitors use a sampling protocol designed to minimise the differences compared to the manual method at the expense of increasing bias compared to the actual conditions in the atmosphere.

\footnotetext{
${ }^{39}$ Recently, the EU has specified a reference method for measurement of $\mathrm{PM}_{2.5}$. However, it might take years until the existing networks are replaced with equipment using the reference method.
} 
Biases between these methods depend on the chemical components in the particles but in general the direction and to some extent the magnitude of the biases are known and presumably could be addressed through sensitivity studies when measuring indicators. Unfortunately, the database is not adequately populated to make a meaningful assessment. After removing all records with a measurement end date prior to 1 January 2013 there remain 1427 records. Sixty-seven percent of the monitors are automated, 27\% are manual, and $6 \%$ are not specified. A larger concern is that the measurement equipment (make and model) is specified for only $41 \%$ of the records including only $38 \%$ of the automated monitors. Thus, the comparability of measurements cannot be rigorously assessed.

For $\mathrm{PM}_{10}, 81 \%$ of the monitors are automated, $17 \%$ are manual, and $2 \%$ are not specified. There are two dominant measurement principles for the automated monitors - Tapered Element Oscillating Microbalance (TEOM) and beta ray attenuation - and these monitors account for $28 \%$ and $54 \%$ of the automated $\mathrm{PM}_{10}$ monitors (most of the remaining $18 \%$ are listed as unknown or are not specified). However, there can still be significant bias within these measurements principle classes and only $44 \%$ of the TEOM monitors and 55\% of the beta monitors have make and model specified.

In summary, comparability for gas pollutant data in AirBase should be good. For particulate matter there might be some issues arising from the use of different measurement methods but insufficient metadata are available to conduct an assessment. Agencies submitting data should be encouraged to provide complete metadata information.

\section{CANDIDATE AIR QUALITY INDICATORS USING GROUND MONITORING DATA}

There are several primary considerations when developing pollutant concentration estimates over large spatial scales to serve as input into a health assessment (Brauer et al. 2012) and thus are relevant to health-based air quality indicators:

o geographic applicability (from local to regional to global);

o spatial resolution and coverage relative to population;

o accuracy and precision;

o applicability to multiple pollutants (e.g. both $\mathrm{PM}_{2.5}$ and ozone);

o ability to estimate exposure changes over time (important for dynamic indicators); and

o sensitivity to assumptions.

This report addresses candidate State indicators ${ }^{40}$ and specifically those based on human population exposures to air pollution. The focus is on producing an indicator primarily based on ground-level monitoring data and assess its adequacy relative to other indicators using alternative data sources.

The candidate indicators would build out from the ground-level monitoring data summarised earlier in this report. There are several approaches to generating population exposures from the monitoring data. Spatial interpolation (e.g. kriging, inverse distance weighting) could be used to generate concentration fields. However, for country and regional level analyses this approach can be problematic when the

\footnotetext{
${ }^{40}$ In reference to the Pressure - State - Response model.
} 
network is sparse and focused solely on urban areas (see e.g. Turkey in Figures 3, 5, and 6 of Section 1). The proposed methodology is discussed in more detail next.

\subsection{Methodology}

This section presents one approach for an indicator based solely on ground-level monitoring data. The objective is to produce a spatially resolved estimate of air pollution concentrations that can be used in combination with population density data to generate measures of air pollution exposure. In the following section the indicator is compared with an alternative approach using models of air pollution generation and dispersion concentration fields derived from satellite images.

The first section characterised the state of ground-level air quality monitoring for the 51 selected countries. While data public availability, geographic coverage, reliability and presumably the comparability of ground-level monitoring data is generally good for most of Europe and North America, for the majority of the remaining selected countries there are moderate-to-severe limitations that would limit the applicability of an indicator centrally based on monitoring data. Having that in mind, if the goal is to proceed with such indicators, then one methodology is as follows:

i) For the available data and pollutant(s) of interest, censor the monitoring data to include only those sites broadly representative of community exposures. For example, using AirBase classifications this would include the background sites and exclude the traffic and industrial sites.

ii) Assign concentration estimates to locations away from the monitors. Two approaches are spatial interpolation and buffer zones. There are several approaches to spatial interpolation but in general the monitor site concentration data are weighted based on distance to the location of interest. More weight is given to monitors close to the point of interest while monitors farther away have less influence. Buffers are spatial zones drawn around each monitor such as circles of a given radius. The concentration at the monitor is assigned to all locations within the buffer. Spatial interpolation has advantages of complete spatial coverage (except perhaps at the extreme edges of the domain) and provides for spatial gradients in concentration which is indeed observed. However, there are challenges in selecting appropriate weighting functions for interpolating air pollution data especially over large spatial scales. For pollutants with significant urban excess, a relatively high density of rural monitors is needed to properly pull down concentrations in the areas between cities. Rural data are often sparse and in such cases it might be necessary to seek proxies for air pollution (e.g. measures of visibility as a proxy for fine particulate matter).

iii) The buffer zone approach assigns the monitored concentration value to all locations in circle around the monitoring location. It has the advantage of not seeking to inform concentrations at large distances from monitors where the representativeness is questionable. However, selection of the buffer zone size is to a large extent subjective. It depends on the pollutant and spatial scale of emission sources that impact the monitoring location. For example, fine particulate matter arises from both primary and secondary sources. As a first approximation, relatively small buffer zones are appropriate for locations with high primary contributions whereas relatively large buffer zones could be used for locations with high secondary contributions. Unfortunately, the mix of primary and secondary contributions varies by location and can change over time; this confounds the process of selecting appropriate buffer sizes. Figures 3-6 show buffer zones of $25 \mathrm{~km}$ radii for urban/suburban monitors and $50 \mathrm{~km}$ radii for rural monitors over Europe. These are likely reasonable for $\mathrm{PM}_{2.5}$ and ozone but might be too large for $\mathrm{PM}_{10}$. Another disadvantage of the buffer zone approach is that there can be large portions of the population with no exposure estimate assigned. 
iv) Considerable effort is needed to develop justifiable buffer sizes. For areas with high monitoring density, there will be monitors located within the buffer zones around other monitors. The variability across such monitors provides an estimate of the estimation error and buffer sizes might be chosen to reduce such variability. Rural monitoring data could be examined over large spatial scales to assess the geographic extent of concentration homogeneity away from urban centres.

The remainder of this methodology is based on the use of buffer zones. Overlapping rural buffer zones would be assigned the area-weighted average of the concentrations for the respective buffers or would be split using, for example, Thiessen polygons. The rural buffer areas that overlap with urban/suburban buffer areas would be erased so that the rural data are used only in those areas outside of the urban/suburban buffers.

\section{Special considerations for $\mathbf{P} M_{2.5}$}

In many countries the $\mathrm{PM}_{10}$ monitoring network is denser than the $\mathrm{PM}_{2.5}$ monitoring network and $\mathrm{PM}_{10}$ can be used as a surrogate for $\mathrm{PM}_{2.5}$ to increase geographic coverage. $\mathrm{PM}_{2.5} / \mathrm{PM}_{10}$ ratios would be calculated for locations with both $\mathrm{PM}_{2.5}$ and $\mathrm{PM}_{10}$ data. Spatial patterns in the ratio would be examined to develop regionally representative ratios for urban and rural areas. The above steps (i)-(iv) would be repeated using the $\mathrm{PM}_{10}$ data to add buffer zones where they do not already exist from the $\mathrm{PM}_{2.5}$ data.

The resulting spatially resolved concentration fields would be overlaid with high spatial resolution population density data to construct the distribution of population exposures to the pollutant. This analysis would also determine the percentage of the population not covered by a buffer zone. ${ }^{41}$

Recommendations for the breakpoints are presented later in this paper. The resulting indicator would be presented as a stacked bar chart for the percentage of population exposed to the various concentration intervals as well as the percentage of population with no estimate provided (i.e. population outside the buffer zones). The percentage of population with no estimate would hopefully decrease in future years as networks grow and/or more data become publicly available. Assuming adequate data, this approach would likely be plausible at the country or region level.

In order to provide an example of an indicator of exposure to pollution, a case study was conducted using $2012 \mathrm{PM}_{2.5}$ annual mean concentrations to construct a country indicator for Spain. Buffers were drawn around $\mathrm{PM}_{2.5}$ urban background and suburban background monitors (25 km radius) and $\mathrm{PM}_{2.5}$ rural background monitors (50 km radius) in France, Portugal and Spain. Thiessen polygons were used to split overlapping urban/suburban buffers and overlapping rural buffers. The portions of rural buffers that overlapped with urban/suburban buffers were erased. High resolution population data for 2010 from the GBD were overlaid to determine the $\mathrm{PM}_{2.5}$ concentration assigned to each population grid and a cumulative distribution of exposures was constructed. Table 1 summarises the results; in this case, about a quarter of the population resides outside a buffer zone and thus the concentration exposure is unclassified. This percentage could be reduced by expanding the buffer sizes or by using $\mathrm{PM}_{10}$ monitoring data as a surrogate with appropriate $\mathrm{PM}_{2.5} / \mathrm{PM}_{10}$ scaling factors.

\footnotetext{
${ }^{41}$ The distribution of population exposures would be classified into concentration intervals similar to Figures 5.1 and 5.3 in OECD (2013), Regions at a Glance.
} 
Table 1. PM2.5 annual concentration exposures for Spain, 2012, using ground-level monitoring data

Using $25 \mathrm{~km}$ buffers for urban and suburban background monitors and $50 \mathrm{~km}$ buffers for rural background monitors.

\begin{tabular}{cc}
\hline $\mathrm{PM}_{2.5}$ annual mean concentration \\
(micrograms $\left./ \mathrm{m}^{3}\right)$ & Population exposed \\
\hline$<10$ & $11 \%$ \\
$10-15$ & $46 \%$ \\
$15-25$ & $15 \%$ \\
$>25$ & $0 \%$ \\
unclassified & $28 \%$ \\
\hline
\end{tabular}

An advantage of this methodology is its simplicity. However, as noted in Section 1, AirBase is one of the most comprehensive ground monitoring networks, for many countries not included in this database there is insufficient data to produce robust measures. Geophysical and socio-economic variables could be included in the modelling, this is the spirit of the GMAPS model historically used by the World Bank. However, as discussed in more detail later in this paper these two approaches are inferior to an indicator based on a hybrid approach using satellite images calibrated with ground measurements.

\section{Measures of interest and indicator presentation}

An advantage of ground-level air quality data from automated monitors is that hourly values are reported and a variety of concentration measures can be constructed. For example, the form of the U.S. ozone air quality standard is based on the annual fourth-highest daily maximum 8-hr concentration, averaged over 3 years. The form of the European Union air quality target for ozone is based on the number of days with daily maximum 8-hr concentration greater than $120 \mu \mathrm{g} / \mathrm{m}^{3}$, averaged over three years. These are just a few of the metrics that can be calculated from hourly data. Standard summary output from AirBase for ozone includes the yearly mean, median, $95^{\text {th }}$ percentile, and $98^{\text {th }}$ percentile of the daily mean, daily 1-hour maximum, and of the hourly data distribution. The $26^{\text {th }}$ highest daily 1-hour maximum and the number of days with daily 1-hour maxima greater than the $120 \mu \mathrm{g} / \mathrm{m}^{3}$ target are also reported. In general, averaging times for air quality standards (or targets) are typically defined to capture the nature of the exposures leading to adverse effects. For example, the US air quality standard was revised in 1997 from a 1-hour averaging time to an 8-hour averaging time because of known adverse effects from prolonged (6- to 8-hour) exposures in addition to acute (1- to 3-hour exposures). The 8-hour standard was set at a level that provided protection against both prolonged and acute exposures.

Table 2 summarises the WHO Air Quality Guidelines (AQG) and Interim Targets (IT). Guidelines are published for four pollutants ( $\mathrm{PM}, \mathrm{O}_{3}, \mathrm{NO}_{2}$ and $\mathrm{SO}_{2}$ ) with two size indicators for $\mathrm{PM}\left(\mathrm{PM}_{2.5}\right.$ and $\left.\mathrm{PM}_{10}\right)$. With the exception of $\mathrm{O}_{3}$ and $\mathrm{SO}_{2}$ there are annual mean averaging times to protect against prolonged exposures as well as 1- to 24-hour means to protect against acute exposures. Data from ground-based automated monitors can in principle be used to estimate exposures for all of the averaging times in Table 2. However, spatial interpolation errors likely increase and representative buffer zone dimensions likely decrease as the averaging time is shortened. Satellite data is only appropriate for long averaging times such as seasonal or annual measures. Chemical transport modelling is typically conducted at hourly resolution and thus has the same capacity as automated monitoring data for time averaging. Again, shorter averaging times likely coincide with higher errors. 
Table 2. World Health Organisation air quality guidelines and interim targets (in

\begin{tabular}{llcl}
\hline Parameter & Averaging Time & Air Quality Guideline (AQG) & $\begin{array}{c}\text { Interim Targets (IT) } \\
(\text { IT-1 / IT-2 / IT-3) }\end{array}$ \\
\hline $\mathrm{PM}_{2.5}$ & Annual mean & 10 & $35 / 25 / 15$ \\
$\mathrm{PM}_{10}$ & 24-hour mean & 25 & $75 / 50 / 37.5$ \\
$\mathrm{O}_{3}$ & Annual mean & 20 & $70 / 50 / 30$ \\
& 24-hour mean & 50 & $150 / 100 / 75$ \\
$\mathrm{NO}_{2}$ & 8-hour mean & 100 & $160 /--/$-- \\
$\mathrm{SO}_{2}$ & Annual mean & 40 & none \\
& 1-hour mean & 200 & none \\
\hline
\end{tabular}

Several factors influence the selection of averaging times to be presented as indicators. For PM, there is greater availability of $\mathrm{PM}_{10}$ data compared to $\mathrm{PM}_{2.5}$ data. However, WHO recommends use of the $\mathrm{PM}_{2.5}$ guideline. The PM guidelines include annual and 24-hour averaging times to reflect adverse effects from long- and short-term exposures, respectively. WHO recommends that annual averages take precedence over 24-hour averages when evaluating guidelines and interim targets. Annual average exposure estimates will likely be more stable than 24-hour average estimates regardless of the methodology used to generate the values (ground-level monitoring data, satellite data, chemical transport models, or some combination of these tools). The longer averaging times also may support the use of large buffer zones around groundbased monitors, and in particular for the rural monitors, leading to a reduction in the fraction of the country population not classified. It was beyond the scope of this work to fully assess the optimum buffer zone size which, unfortunately, likely varies by pollutant and perhaps also by location. As described in Section 3, GBD output for $\mathrm{PM}_{2.5}$ are annual averages from a hybrid satellite-CTM analysis with calibration using ground-based monitoring data. There are also plans to generate $\mathrm{NO}_{2}$ output, perhaps starting with GBD 2015, although a commitment has not been made at this time.

For ozone, the WHO AQG is an 8-hour mean whereas the GBD outputs are seasonal (3 month) averages of the daily 1-hour maximum ozone concentrations because this was the main exposure metric used in the epidemiological studies supporting the GBD assessment. The GBD output for ozone is from chemical transport modelling at hourly resolution so it would be straightforward to process the raw output into a format consistent with the WHO AQG.

It is recommended that the OECD adopt the averaging times listed in Table 2 and focus on the longest averaging times which correspond to prolonged exposures. The recommended approach is to present the State indicators as the percent of population exposed to a specified level of air pollution. A stacked bar chart approach $^{42}$ is recommended with WHO AQGs and ITs used as the interval breakpoints to the extent practicable. In some cases, such as $\mathrm{O}_{3}$ and $\mathrm{NO}_{2}$, additional breakpoints can be added to provide more details about the distribution of population exposures.

\footnotetext{
${ }^{42}$ Similar to Figures 5.1 and 5.3 in OECD (2013) Regions at a Glance.
} 


\section{DISCUSSION}

The objectives of this paper were to review availability of relevant data on air pollutant concentrations from ground monitoring stations across all OECD and G20 countries, document the data sources identified (measurement method, representativeness, reliability, periodicity, timeliness, temporal and geographical coverage, pollutants covered and attributes measured, webpage from where data can be downloaded, etc.), and provide guidance on compiling the data more generally. To a large extent these objectives could not be achieved because outside of Europe and North America the data are not publicly available or when publicly available the data could only be queried site-by-site. It was beyond the scope of this study to conduct such queries and assemble the resulting information. Many countries appear to have country-level databases that are used for such queries and thus it might be possible to obtain consolidated datasets upon request. In other cases, however, it is not clear that county-level consolidated databases exist. Data and metadata for Europe, Canada, and the United States are publicly available and in principle could be used for the production of air quality indicators. For the remaining countries, however, there would still remain numerous gaps and the effort needed to assemble a suitable database would be substantial. As discussed next in this section this finding has direct implications to the approaches OECD should take to produce robust and comprehensive air quality indicators.

This Section proposes alternative approaches that are likely to yield more adequate measures of exposure to air pollution. Two of these approaches to calculating pollution concentrations, the World Bank (WB) approach and the Global Burden of Disease (GBD) approach are discussed next. While the WB approach uses monitoring data as one of many geophysical and socio-economic parameters to model $\mathrm{PM}_{10}$ concentrations in cities, the GBD approach fuses chemical transport modelling and satellite data to generated $\mathrm{PM}_{2.5}$ concentration fields which are calibrated using ground monitoring data.

\subsection{The World Bank approach}

WB has historically produced measures of the country-level cost of health damages from exposures to outdoor $\mathrm{PM}_{10}$ using the Global Model of Ambient Particulates (GMAPS) (Cropper and Khanna, 2014). The indicator is annual average $\mathrm{PM}_{10}$ concentrations in cities with population of at least 100000 . GMAPS estimates city-level $\mathrm{PM}_{10}$ concentration using country-level per capita energy consumption by fuel type, population density and per capita GDP; city level population, population density and GDP/ $/ \mathrm{km}^{2}$; meteorological variables (held constant from year-to-year); city-specific time trends; and country fixed effects. This is a dynamic indicator which currently covers the period 1985-2011. The model is estimated using data from 1195 cities in 98 countries and is subsequently applied to an additional 2000 cities in an additional 98 countries. These city-level PM $_{10}$ concentrations and country-level urban population weighted average $\mathrm{PM}_{10}$ concentrations are published (World Bank, 2015). Populations outside of the modelled cities are not included and thus are not factored into the air pollution health damages estimates (Cropper and Khanna, 2014).

Country- or finer-level $\mathrm{PM}_{2.5}$ and ozone concentrations are generated by the Institute for Health Metrics by the Global Burden of disease (GBD) team. IHME periodically conducts the Global Burden of Disease study which includes measures of adverse health outcomes from exposure to outdoor air pollution. An intermediate product are high resolution $\left(0.1^{\circ} \times 0.1^{\circ}\right)$ global maps of $\mathrm{PM}_{2.5}$ and ozone. ${ }^{43}$ These data could be used to construct country-, region- or city-scale estimates of population exposure to $\mathrm{PM}_{2.5}$ and ozone. A study by Resources for the Future (RFF) recommended the WB adopt the GBD methodology to

${ }^{43} 0.1^{\circ}$ is approximately $10 \mathrm{~km}$ at mid-latitudes. 
replace its current approach described above (Cropper and Khanna, 2014) and indeed this has occurred (Brauer and Cohen, 2015).

In addition, the OECD could consider using the indicators of country-level air pollution health damages developed by WB and/or country-level health impacts developed by the GBD team. An assessment of such indicators is beyond the scope of this study.

\subsection{The Global Burden of Disease approach}

Various indicators have been presented in the literature with a recent emphasis on fusing satellite data with chemical transport modelling (CTM) to obtain global air pollutant concentration fields. This approach has been motivated by the paucity of monitoring data including, but not limited to, developing countries (van Donkelaar et al. 2010). For example, Rao et al. (2012) used the TM5 chemical transport model (CTM) to generate global $\mathrm{PM}_{2.5}$ concentration fields at $1^{\circ} \times 1^{\circ}$ resolution as input to a disease burden assessment for deaths and disability adjusted life years (DALYs). Prud'homme et al. (2013) used satellite-derived aerosol optical depth (AOD) combined with the Goddard Earth Observing System CTM (GEOS-Chem) to generate $\mathrm{PM}_{2.5}$ and $\mathrm{NO}_{2}$ concentration fields over Canada at $0.1^{\circ} \times 0.1^{\circ}$ resolution as input to a study of associations between air pollution and respiratory and allergic health outcomes. Risk estimates based on this approach and nearest-neighbour monitors (40 km search radius) were similar for urban areas with the remote sensing approach having the added value of providing risk estimates for rural areas with no nearby monitors. Evans et al. (2013) used satellite-derived AOD combined with the GEOS-Chem CTM to generate global $\mathrm{PM}_{2.5}$ concentration fields at $0.1^{\circ} \times 0.1^{\circ}$ resolution as input to a disease burden assessment for mortality attributable to $\mathrm{PM}_{2.5}$. Brauer et al. (2012) fused satellite-derived AOD and CTM to generate global $\mathrm{PM}_{2.5}$ concentration fields which were calibrated using ground-level monitoring data. Their methodology is summarised in more detail below.

The GBD2010 methodology for $\mathrm{PM}_{2.5}$ fuses satellite-based estimates, chemical transport model (CTM) estimates, and ground-level monitoring data to generate global concentration fields with high spatial resolution. A skeletal description of the methodology for $\mathrm{PM}_{2.5}$ is as follows (Brauer et al. 2012; Cropper and Khanna 2014):

i. Ground-level $\mathrm{PM}_{2.5}$ concentrations are estimated by fusing satellite-derived AOD with the GEOS-Chem CTM. The CTM is used to generate scaling factors to convert AOD to ground-level concentrations. The scaling factors are generated at $2.5^{\circ} \times 2.5^{\circ}$ resolution and are interpolated to $0.1^{\circ} \times 0.1^{\circ}$ resolution and then applied to the satellite-derived AOD data.

ii. Ground-level $\mathrm{PM}_{2.5}$ concentrations are also estimated using the TM5 CTM at $1^{\circ} \times 1^{\circ}$ resolution. A sub grid parameterisation is used to account for spatial variability at finer spatial resolution using population density as a proxy for emissions and the resulting model output is at $0.1^{\circ} \times 0.1^{\circ}$ resolution.

iii. Ground-level $\mathrm{PM}_{2.5}$ estimates from steps (1) and (2) are averaged. Ground-level measurement data from select monitoring sites are used to calibrate the concentration estimates (this places a much lower burden on the extensiveness of monitoring data compared to the Monitoring Indicator methodology described in Section 2).

iv. $\quad \mathrm{PM}_{2.5}$ concentration values above a threshold level of $10 \mu \mathrm{g} / \mathrm{m}^{3}$ are regressed on the modelled ground-level $\mathrm{PM}_{2.5}$ estimates using a power law relationship. The resulting power law equation coefficients are then used to estimate ground-level $\mathrm{PM}_{2.5}$ at $0.1^{\circ} \times 0.1^{\circ}$ resolution across the globe.

v. These steps are performed with annual averages. 
Additional steps are used to generate the GBD disease burden estimates such as deaths, YLL, and DALYs (Lim et al. 2012) but the pollutant concentration estimates from step (v), along with population data allocated to the same grids, are a publicly available intermediate product that could be used by OECD. For the OECD indicator the spatially resolved pollutant concentration estimates from step (v) can be combined with the spatially resolved population data, generated by the GBD team on the same grid, to generate distributions of population exposures for each country or region.

Additionally, ozone concentration fields are generated at $1^{\circ} \times 1^{\circ}$ resolution using the TM5 CTM with no calibration using ground-level monitors.

These analyses are performed by the GBD team for the Institute for Health Metrics and Evaluation (IHME). GBD estimates are available for 1990, 1995, 2000, 2005, 2010 and will soon be available for 2013. Thus, a dynamic indicator could be presented such as changes in country population exposures over time. Historical periods are periodically re-evaluated to minimise methodological inconsistencies and improve the confidence in dynamic indicators. For example, Brauer et al. (2012) present results for both 1990 and 2005 that were generated using a consistent methodology. Starting with 2013 the estimates will be produced annually (Brauer and Cohen, 2015).

The GBD approach has several advantages. It has global coverage and thus can be used to generate indicators for each of the selected countries. One weakness has been the relatively limited data set of ground-level measurements that were used to calibrate the 2005 model. Brauer et al. (2012) used 2005 ground-level monitoring data (2004-06 data if 2005 data were not available) from 679 locations that represent urban background environments. $\mathrm{PM}_{2.5}$ data were available for $70 \%$ of the sites and $\mathrm{PM}_{2.5}$ was estimated from $\mathrm{PM}_{10}$ measurements and inferred $\mathrm{PM}_{2.5} / \mathrm{PM}_{10}$ ratios for the remaining sites. The spatial distribution was: 42\% North America, 27\% Asia/Australasia; 25\% Europe (but only 4\% in Central Europe and none in Eastern Europe); 4\% Latin America; and 3\% Africa/Middle East. The GBD team has been addressing this weakness by bringing in additional ground-level monitoring data. For example, the 2013 assessment includes several dozen stations in China with these data obtained by hourly "scraping" from the real-time data that are posted to the web to assemble a dataset for constructing annual averages (Brauer and Cohen, 2015). In future updates the monitoring data set could be further expanded; opportunities to do so include, but are not limited to, a recently deployed global network designed to provide data for improving estimates of ground-level $\mathrm{PM}_{2.5}$ from satellite AOD data. This network - the Surface Particulate Matter Network (SPARTAN) - was designed with the intent to evaluate and enhance satellite-based $\mathrm{PM}_{2.5}$ estimates for global health studies (Snider et al., 2015). To date there are fourteen stations in strategically defined locations and the intent is to further grow the network.

Several additional refinements to the GBD methodology are underway (Brauer and Cohen, 2015). In addition to significantly expanding the ground-level monitoring dataset used for calibration, the $\mathrm{PM}_{2.5}$ refinements will include more sophisticated methods to merge the ground-level data with the CTM and satellite data, adding additional CTMs, and refining the spatial resolution. For ozone there are plans to integrate ozone measurement data with the CTM modelling. Additional pollutants eventually will be included with nitrogen dioxide $\left(\mathrm{NO}_{2}\right)$ possibly added as early as the 2015 assessment. Finally, from a policy-making standpoint there is value in having indicators that are harmonised across various organisations. The GDB concentration fields have recently been adopted by WB to replace the GMAPS model in their air pollution damages assessment, and have been adopted by the United States Environmental Protection Agency for use in their international Environmental Benefits Mapping and Analysis Program (BenMAP) program that calculates disease burdens (Brauer and Cohen, 2015). There is a long history of synergy between WHO and GBD assessments starting with WHO leading the process for GBD 2000. That assessment was based on the WB air pollution in cities economic model summarised above. WHO has periodically updated its air pollution in cities measurement database and now produces its own health damages indicators. Their most-recent assessment used the GBD 2010 exposure estimates. 
GBD 2013 uses the WHO air pollution in cities measurement database along with additional measurement data. Both GBD and WHO are working to improve the integration of air quality measurement data with other data (e.g. satellite, CTM) to generate exposure estimates, and it is likely that very similar if not identical methodologies will be adopted (Brauer and Cohen, 2015). Some example indicators calculated using the GBD approach are shown in the Annex for demonstration purposes. 


\section{CONCLUSIONS}

This paper focused on an assessment of ground-level air quality monitoring data in all OECD and G20 countries and recommendations for country (or finer spatial scale) exposure indicators based on these data. Several deficiencies were identified including the limited public availability of data and incomplete geographic coverage. The current World Bank (WB) approach to air quality indicators combines groundlevel air quality monitoring data with other sources of environmental, geophysical and socio-economic data. Cropper and Khanna (2015) critically reviewed the WB approach and deemed it inferior to the Global Burden of Disease (GBD) approach generated for the Institute for Health Metrics and Evaluation (IHME). While the main focus of this study was on exposure indicator methodology based solely on ground-level air quality data and spatially-resolved population data (Sections 1 and 2), it is proposed that the GBD approach would better suit the needs of the OECD (Section 3).

The following approach is recommended for OECD to refine their air quality indicators.

i. $\quad$ Produce an indicator for particulate matter smaller than $2.5 \mu \mathrm{m}$ aerodynamic diameter $\left(\mathrm{PM}_{2.5}\right)$ because, among the five pollutants for which the World Health Organization (WHO) has set Air Quality Guidelines (AQG), $\mathrm{PM}_{2.5}$ is accepted to be of greatest global concern for adverse health outcomes from chronic exposures. There are also known adverse outcomes for elevated acute exposures. If a second indicator is included, ozone $\left(\mathrm{O}_{3}\right)$ is recommended because of its adverse impact on respiratory health.

ii. Global spatially-resolved $\mathrm{PM}_{2.5}$ and $\mathrm{O}_{3}$ concentration fields are now available and should be used as the foundation for estimating population exposures. Specifically, the GBD team generates these concentration fields as an intermediate product for the GBD assessment. These fields have high spatial resolution $\left(0.1^{\circ} \times 0.1^{\circ}\right)$ and are derived from the fusion of satellite data and air quality modelling with ground-level monitoring data used to calibrate the estimates.

iii. The high spatial resolution concentration fields should be combined with population density data to generate county- and region-level (and even city-level if so desired) population exposures distributions. The population exposures distributions should be classified by concentration levels with the WHO AQG and Interim Target (IR) concentration values used as breakpoints when practicable.

There are several advantages to using the GBD estimates. The World Bank and the United States Environmental Protection Agency have adopted the GBD estimates for global assessments and there is extensive coupling to the current World Health Organization (WHO) methodology and estimates. Adoption of the GBD methodology by the OECD would further advance harmonisation of metrics across organisations. Historical estimates are publicly available (1990, 1995, 2000, 2005, and 2010) and can be used to construct dynamic indicators. The 2013 GBD concentration fields for $\mathrm{PM}_{2.5}$ and ozone have been produced and should be available in 2015 and there is a plan to annually produce and publish estimates. The underlying methodology has been - and will continue to be - improved over time. Finally, these measures are used as inputs for disease burden indicators such as the country-level deaths, life years lost (YLL), and disability adjusted life years (DALY) generated by the GBD team that have been used by the OECD in prior studies (OECD, 2014). 


\section{REFERENCES}

Brauer M., M. Amann, R.T. Burnett, A. Cohen, F. Dentener, M. Ezzati, S.B. Henderson, M. Kryzanowski, R.V. Martin, R. Van Dingenen, A. van Donkelaar and G.D. Thurston (2012), "Exposure assessment for estimation of the global burden of disease attributable to outdoor air pollution”, Environmental Science \& Technology, 46 (2), pp. 652-660, Washington, D.C.

Brauer M. and A. Cohen (2015), personal communication.

Cropper, M. and S. Khanna (2014), “How should the World Bank estimate air pollution damages?” Report RFF DP, pp. 14-30, Resources for the Future, Washington, DC.

Evans J., A. van Donkelaar, R.V. Martin, R. Burnett, D.G. Rainham, N.J. Birkett and D. Krewski (2013), "Estimates of global mortality attributable to particulate matter air pollution using satellite imagery", Environmental Research, 120, pp. 33-42.

Kjellsrom T. and C. Corvalan (1995), "Framework for the development of environmental health indicators”, Wld. Hlth. Statist. Quart., 48, pp. 144-154.

Lim S.S., T. Vos, PhD, A.D. Flaxman, G. Danaei, K. Shibuya et al. (2012), “A comparative risk assessment of burden of disease and injury attributable to 67 risk factor clusters in 21 regions, 1990-2010: a systematic analysis for the Global Burden of Disease study 2010”, The Lancet, 380, No. 9859, pp. 2224-2260.

Mackie A., I. Haščič and M. Cárdenas Rodríguez (2016), "Population exposure to fine particles: methodology and results for OECD and G20 countries”, OECD Green Growth Papers, No. 2016/02, OECD Publishing, Paris.

OECD (2014) The Cost of Air Pollution: Health Impacts and Road Transport, OECD Publishing, Paris. http://dx.doi.org/10.1787/9789264210448-en.

OECD (2013), Regions at a Glance 2013, OECD Publishing, Paris, http://dx.doi.org//10.1787/reg_glance-2013-en.

Prud'homme G., N.A. Dobbin, L. Sun, R.T. Burnett, R.V. Martin, A. Davidson, S. Cakmak, P.J. Villenueve, L.N. lamsal, A. van Donkelaar, P.A. Peters and M. Johnson (2013), "Comparison of remote sensing and fixed-site monitoring approaches for examining air pollution and health in a national study population”, Atmospheric Environment, 80, pp. 161-171.

Rao S., V. Chikov, F. Dentener, R. Van Dingenen, S. Pachauri, P. Purohit, M. Amann, C. Heyes, P. Kinney, P. Kolp, Z. Kilmont, K. Riahi and W. Schoepp (2012), "Environmental modeling and methods for estimation of the global health impacts of air pollution", Environmental Modeling \& Assessment, 17, pp. 613-622.

Snider et al. (2015), "SPARTAN: a global network to evaluate and enhance satellite-based estimates of ground-level particulate matter for global health applications", Atmospheric Measurement Technologies, 8, pp. 505-521.

Van Donkelaar A, R.V. Martin, M. Brauer, R. Kahn, R. Levy, C. Verduzco and P.J. Villeneuve (2010), "Global estimates of ambient fine particulate matter concentrations from satellite-based aerosol optical depth: development and application”, Environmental Health Perspectives, 118, pp. 847-855.

World Bank (2015), World Development Indicators: PM10, http://data.worldbank.org/indicator/EN.ATM.PM10.MC.M3. 


\begin{abstract}
ANNEX
Example indicators (for demonstration purposes only)

1. Brauer et al. (2012) build a compelling case that among the pollutants with WHO AQGs, primarily $\mathrm{PM}_{2.5}$ and secondarily $\mathrm{O}_{3}$ are the most important from a disease burden perspective. Thus, it is recommended that $\mathrm{PM}_{2.5}$, and possibly $\mathrm{O}_{3}$, be the indicators reported by OECD. It is also recommended that the GBD air pollutant concentration fields be used. These fields are considered to be the best estimates available at this time and at the global level are far superior to approaches that are primarily derived from ground-level monitoring data. They have been adopted by other organisations for country-level analysis and there is a plan for annual production and publishing of these concentration fields. Population data are provided on the same spatial resolution as the air quality data and thus distributions of population exposures can be readily constructed.
\end{abstract}

2. For $\mathrm{PM}_{2.5}$ it is recommended that the indicators be presented as stacked bar charts of population exposures by concentration with concentration interval breakpoints based on the WHO AQGs and Interim Targets (ITs). For ozone the GBD team currently provides seasonal averages of the daily 1-hour maximum ozone concentration rather than daily maximum 8-hour means which is the form of the WHO AQG. Specifically, the GBD metric is the maximum from the set of rolling 3-month averages of the daily 1-hour maximum ozone concentrations. However, these measures are constructed from hourly modelled concentrations and it would be straightforward for the GBD team to generate spatially resolved daily maximum 8-hour means consistent with the form of the WHO AQG.

3. Annex Figure A1 shows the $\mathrm{PM}_{2.5}$ population exposure indicator using the GBD global concentration estimates for 2010. Countries such as Saudi Arabia are strongly impacted by desert dust and the GBD team also produces no-dust $\mathrm{PM}_{2.5}$ concentration estimates which could be used to isolate the dust contribution. This Figure along with the underlying concentration distributions, updated when the 2013 GBD data are available, is recommended for presentation as the primary state indicator for exposure to air pollution.

4. Annex Figure A2 shows the ozone population exposure indicator using the GBD global concentration estimates for 2010. This figure as presented suffers from the lack of correspondence to the WHO AQG and IT for ozone and thus is more difficult to interpret in a policy context than the $\mathrm{PM}_{2.5}$ figure. However, as previously noted, the GBD team could generate modelled ozone concentrations in the form of the WHO AQG metric by additional post-processing of their hourly modelled output. This figure along with the underlying concentration distributions, updated when the 2013 GBD data are available, is recommended for presentation as a secondary state indicator for exposure to air pollution. 
Figure A1. Population exposures to outdoor fine particulate matter (PM2.5) in 2010 using GBD2010

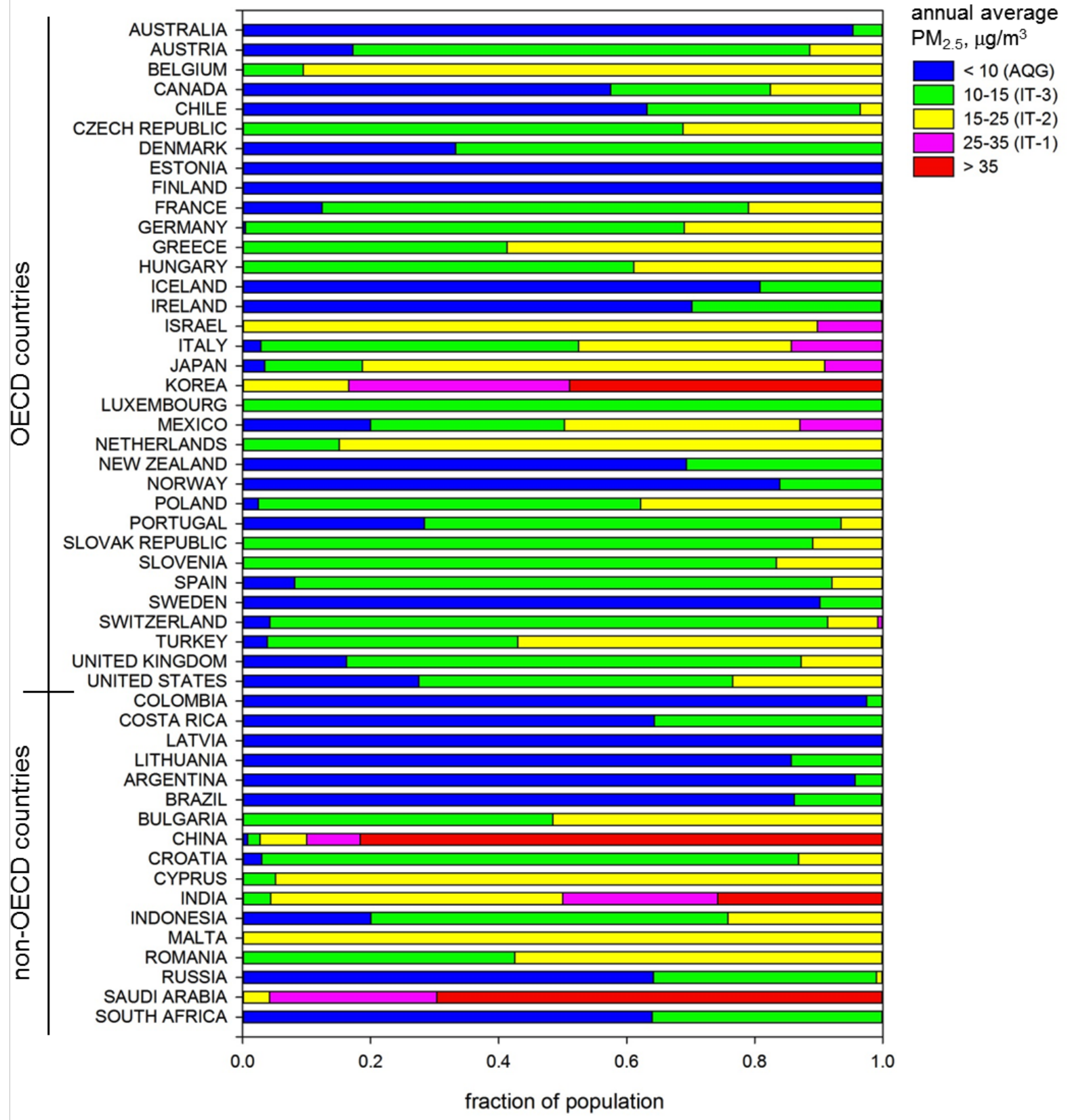

Note: The upper bound of each concentration interval corresponds to WHO Air Quality Guideline (AQG) or WHO Interim Target (IT) levels.

Source: Global Burden of Disease (GBD) global concentration field estimates from Brauer et al. (2012). 
Figure A2. Population exposures to outdoor ozone (O3) in 2010 using GBD2010

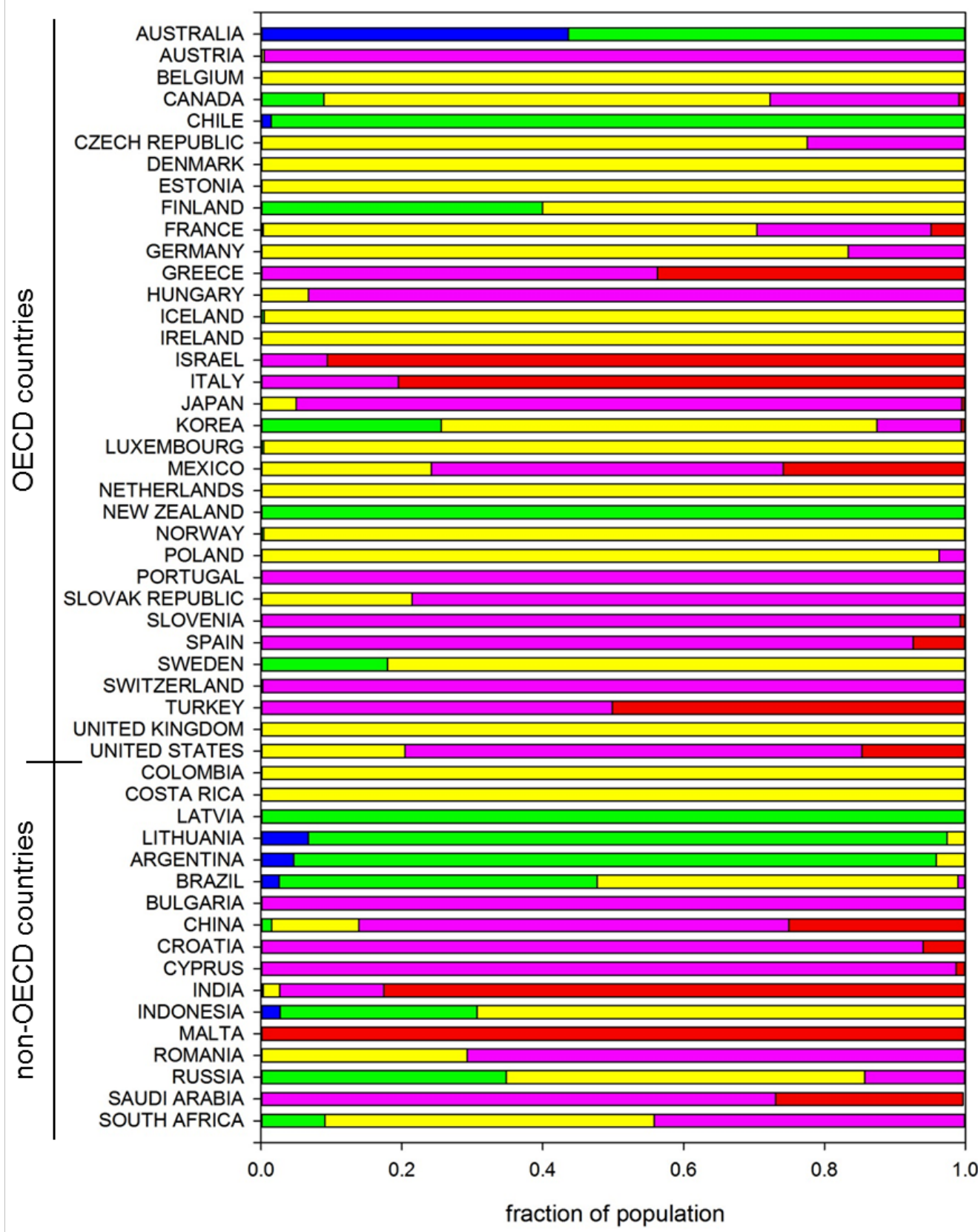

seasonal hourly

maximum $\mathrm{O}_{3}$, $\mathrm{ppb}$

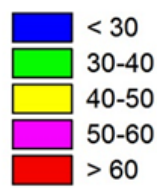

Note: Ozone calculated as the maximum of the running three-month averages of daily one hour maximum values.

Source: Global Burden of Disease (GBD) global concentration field estimates from Brauer et al. (2012). 
www.oecd.org/greengrowth 